\title{
Current Perspectives on the Assessment and Management of Gait Disorders in Parkinson's Disease
}

\author{
Matthew D Smith ${ }^{1,2}$ \\ Danielle E Brazier (D) \\ Emily J Henderson ${ }^{1,2}$
}

'Population Health Sciences, Bristol Medical School, University of Bristol, Bristol, UK; ' ${ }^{2}$ Older People's Unit, Royal United Hospital NHS Foundation Trust, Bath, UK
Correspondence: Matthew D Smith Email matthew.smith@Bristol.ac.uk

\begin{abstract}
Gait dysfunction is a key defining feature of Parkinson's disease (PD), and is associated with symptoms of freezing and an increased risk of falls. In this narrative review, we cover the putative mechanisms of gait dysfunction in PD, the assessment of gait abnormalities, and the management of symptoms caused by the inherent difficulty in walking. Our understanding of the causes of gait problems in PD has progressed in recent times, moving from neurocognitive theory to correlates of affected neuronal pathways. In particular, this can be shown to correspond with abnormalities in responses to dual-task paradigms and dysfunction in cholinergic signaling. Great progress has been made in the sophistication and precision of gait assessment; however, it has firmly remained in the research domain. There is significant momentum behind wearable technologies that can be used by patients in their own environment, acting as digital biomarkers that can not only reflect progression but also independently discriminate PD from non-PD individuals. The treatment of gait dysfunction has historically relied on physical therapies and training combined with a view to mitigating the impact of such consequences as falls. Pharmacological therapies that are the mainstay of treatment in PD have tended to address symptoms like bradykinesia; however, optimization of dopaminergic therapies likely has a positive effect on quality of gait. Other targets have been assessed with the goal of improving gait, of which medications that improve cholinergic signaling appear most promising. Neuromodulation techniques are increasingly used in the form of deep-brain stimulation; however, standard targets, such as the globus pallidus interna, have a modest effect on gait. Considerable benefit has been seen through targeting the pedunculopontine nucleus, and a dualtarget approach may be warranted. Stimulation of the spinal cord and brain through direct or magnetic approaches has been assessed, but requires further evidence.
\end{abstract}

Keywords: falls, freezing of gait, gait assessment, neurodegeneration, neuropathology

\section{Introduction}

Parkinson's disease (PD) affects many individuals, and is the second-most common neurodegenerative disease in the UK. ${ }^{1}$ Historically defined by the clinical triad of bradykinesia, rigidity, and tremor, postural instability is the fourth cardinal feature. Emergence and evolution of instability occurs with disease progression, which correlates with Hoehn and Yahr staging. ${ }^{2}$ Dysfunction in both gait and balance are potent contributors to postural instability, which is inextricably linked to the occurrence of falls. Gait dysfunction is one of the most disabling symptoms for people with the condition, and exerts a greater effect on quality of life than dyskinesia and motor complications. ${ }^{3,4}$ The prevalence and burden of falls is widely 
recognized: almost half of people with PD experience a fall in a 3-month period. ${ }^{5,6}$ Falls result in soft-tissue injuries, head injuries and fractures with the associated need for hospitalization. ${ }^{7}$ Fear of falling is frequently underrecognized but jeopardizes independence by eroding an individual's confidence in their ability to walk. Despite a growing body of evidence examining interventions for fear of falling in the PD population, ${ }^{8}$ this has a considerable effect on quality of life for individuals with a postural imbalance and gait disorder (PIGD) subtype. Symptoms of gait dysfunction are at best only partially ameliorated by a majority of pharmacological therapies used for the treatment of $\mathrm{PD}$, and in the later stages of the condition, dopaminergic medications can paroxysmally worsen gait, such as by causing episodes of "on" freezing."

The aim of this review is to define the features of gait dysfunction in PD and the phenomena that contribute to this problem and provide current perspectives on gait assessment and treatment strategies.

\section{Mechanisms of Normal Gait}

Walking is of deep-rooted cultural and behavioural importance to human beings, and for many it can facilitate creative thought and enjoyment. However, ambulating upright is a complex feat of biology that has eluded replication in artificially designed machines. Reflecting on the important philosophical, lifestyle, and political importance of walking can give valuable insight as to why impairment in gait leads to such profound negative effects on quality of life.

A multitude of neurological resources are required to generate gait. Normal walking utilizes processing at all levels of the central nervous system in healthy individuals, spanning the cortical brain to the spinal cord. This converts a volitional concept into an automatic process, involving postural tone, balance, and limb movement.

At the most basic level, gait control starts in the spinal cord, where central pattern generator $(\mathrm{CpG})$ circuits are located that induce rhythmic activation of complementary flexor and extensor muscles. ${ }^{10}$ These initiate stepping motions, responsible for the primordial stepping reflexes seen in infants that are lost as development progresses and respond directly to proprioceptive feedback, affording the spinal cord significant processing capacity.

The brain-stem and midbrain regions have extensive connection to the effector circuits of the spinal cord and are increasingly being appreciated for their role in locomotion. The mesencephalic locomotor region (MLR) in particular has been of interest, containing structures including the predominantly cholinergic pedunculopontine nucleus (PPN), which is an output target of the basal ganglia. ${ }^{11}$ These regions are involved with postural control, but also act to directly coordinate the $\mathrm{CpG}$ circuits of the spinal cord. Together, these lower-order processing centers work in a highly connected state, likely providing the automaticity of gait seen in healthy individuals and reducing the resources required from higher-order centers, such as the frontal cortex.

Ultimately, voluntary initiation of walking is consciously initiated by the primary motor cortex. However other secondary motor centers, such as the premotor cortex, supplementary motor area, and posterior parietal cortex, are involved in the organization of movement. These further cortical areas likely integrate sensory feedback to allow motor planning. ${ }^{12}$ Basal ganglia circuitry help integrate sensory information, with outputs to the motor cortex via the thalamus implicated in facilitating the automatic execution of learned movements.

Although a defined primary gait pathway as described has been well characterized traditionally through animal and lesional studies, increasing evidence exists for parallel motor pathways that facilitate gait separately from the aforementioned. A conceptual representation of this is through kinesia paradoxa in PD, where an individual with marked gait dysfunction experiences difficulty with basic tasks, such as walking, but is able to run or play sport proficiently. ${ }^{13}$ This may differentiate the activation of cognitively driven versus emotionally driven pathways that facilitate contextually different types of movement, utilizing differing pathways through common neuroanatomical structures that correspond to a ventral and dorsal motor system. ${ }^{14}$ The basal ganglia may be involved in switching between such pathways, ${ }^{13}$ with the relative degeneration of the posterior putamen involved in automatic rather than goal-directed movements a potential cause of gait dysfunction in PD. ${ }^{15}$ The cerebellum is increasingly thought to contribute to gait function, having a potential higher processing role independent of the cortices, acting on feedback, and facilitating predictive adaption of gait within the environment. ${ }^{12}$ The mechanisms that allow individuals to walk with ease are complex and highly networked, reliant on one another's function to facilitate automatic yet stable gait. 


\section{Nature of Gait Dysfunction in Parkinson's Disease}

Despite being a hallmark feature of PD, gait dysfunction is complex and evolves as the disease progresses. A single unifying cause of difficulty walking is not seen in the condition and is dependent on various interacting processes. Giladi et al described the useful conceptual framework classifying gait dysfunction as continuous or episodic. ${ }^{16}$ Continuous gait dysfunction represents a persistent disturbance of locomotion, whereas episodic dysfunction is intermittent. There are associations between continuous and episodic dysfunction, and gait manifestations in both categories can present in an individual. Dysfunction in gait can be further broken down into domains, in which specific components of gait are abnormal and typify PD: pace, rhythm, variability, asymmetry, and postural control. ${ }^{17}$ These interact with the unpredictable episodic features to produce the complex picture of gait dysfunction in PD. This is summarized in Figure 1.

\section{Continuous Gait Dysfunction}

Continuous gait dysfunction constitutes permanent and progressive change to locomotion. This is predictable, and often patients compensate for this, eg, with the use of walking aids. Continuous gait changes encompass the effect of some of the core underlying features of PD: bradykinesia, rigidity, and truncal instability, which act to adversely affect gait. The effects of dopaminergic medication in addressing such symptoms as bradykinesia and stiffness can be dynamic, as reflected in the functionally defined motoric on and off states. This fluctuation can often tend to be stereotypical over a period of months to years, and is thus considered within the domain of continuous dysfunction. However, a flaw of this model is that this does not always hold true, with on and off states not always predictable in some individuals.

Continuous gait changes manifest in a number of measurable aberrations that can be described in terms of changes to a number of conceptual moments, the first moment representing changes in mean values, such as gait speed and stride length, the second moment representing changes in variability and in the long-term scaling of gait (overall alteration in stride dynamics). ${ }^{18}$ Gait speed is reduced in PD, even early during the disease course. ${ }^{19}$ This results from impairment in the generation of normal stride length, and is compensated by increased cadence (number of steps/time). ${ }^{20}$ Gait variability is a metric that reflects the fluctuation in spatiotemporal parameters of gait on a stride-to-stride basis. Not usually evident without quantitative gait measurement, this inconsistency of gait is seen in other degenerative conditions, including dementia and frailty, ${ }^{21}$ and the increasing variability of gait parameters correlates positively with disease progression in PD. ${ }^{22,23}$ Gait variability correlates with the risk of falls,

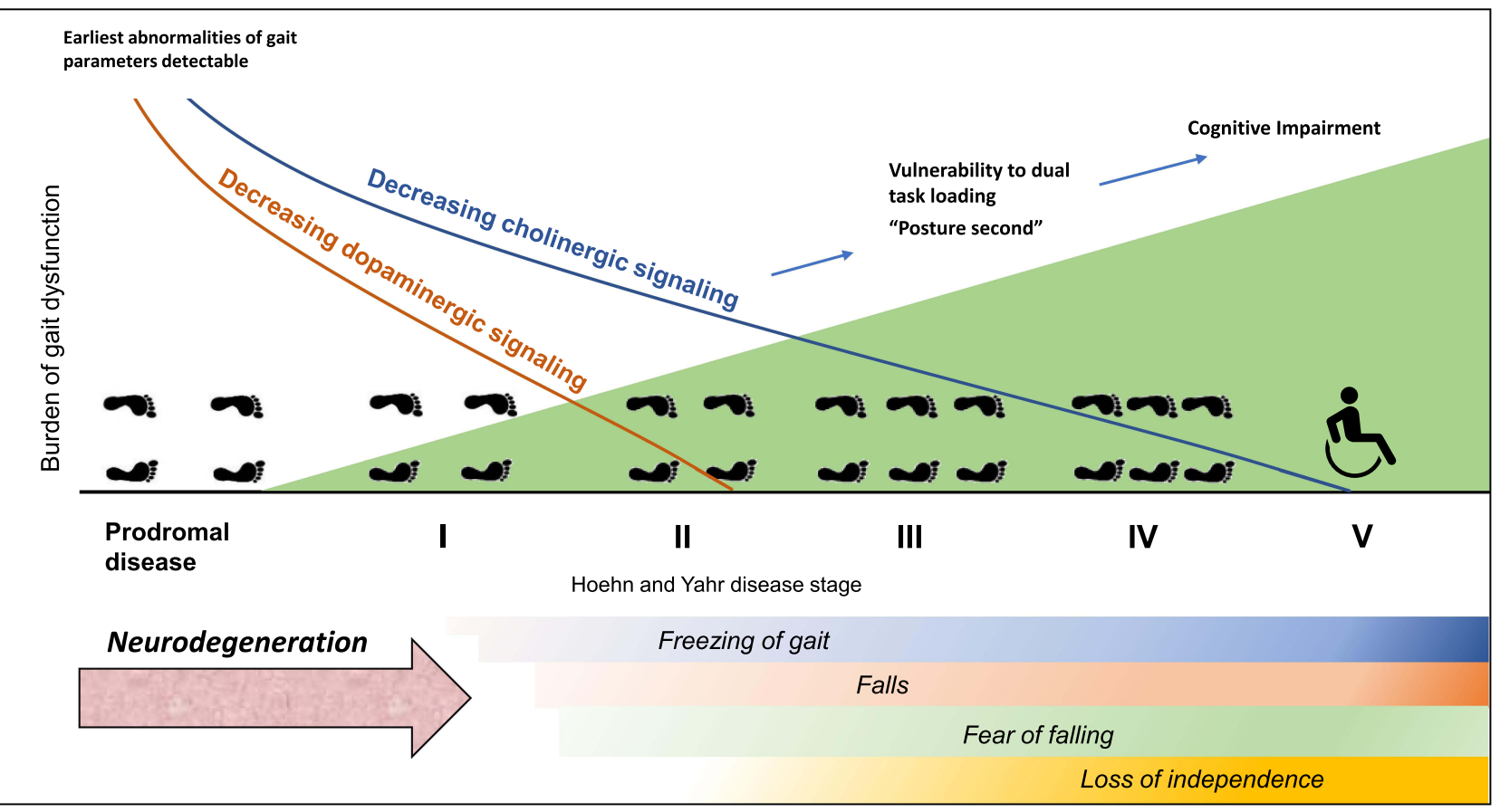

Figure I Schematic of gait dysfunction over disease course. 
a stronger association than with absolute gait speed. ${ }^{24}$ Gait is less symmetrical in PD, and can be quantified by such indices as the Phase Coordination Index, reflecting the reduced coordination of left- and right-heel strikes. ${ }^{25}$ Irregularity can also be seen in the quality of gait over a period of movement. In normal gait, a fractal-like pattern is demonstrated, where a single stride resembles another; however, this gait memory breaks down in PD. This leads to random fluctuations, suggesting that each stride is initiated individually in $\mathrm{PD},{ }^{18}$ analogous with the loss of fluidity and automaticity of gait that is seen. This has been observed directly in older adults, using autocorrelation techniques in which gait cycles have been shown to vary excessively from those that had occurred previously. ${ }^{26}$ Overall, the complexity of gait (measured as entropy in more recent studies) has been shown to decrease with progressive stages of $\mathrm{PD},{ }^{27}$ perhaps representing the outcome of an inability to adapt to changes in the environment. The cumulative effect of underlying dysfunctional gait processing yields inconsistency of gait and loss of adaptability, which in turn is a potent contributor to fall risk.

Alterations in quantitative gait parameters are consistently seen in PD, as replicated in many studies. ${ }^{28}$ This has been found to be present not only in the early stages of $\mathrm{PD}^{17}$ but also in the prodromal stages before the onset of obvious motor symptoms (such as in those with REM sleep-behavior disorder $[\mathrm{RBD}]) .{ }^{29}$ Concordantly, the occurrence of falls can be seen early on in a subset of patients, ${ }^{30}$ associated with an increased risk of fracture even prior to diagnosis in a significant number. ${ }^{31}$ Early parameters of gait dysfunction are specific enough to allow machine learning-determined discrimination of individuals with PD versus similar-age controls. Given the nature of gait parameters to change with disease progression, measuring these could constitute a useful functional biomarker for both the diagnosis of PD and monitoring of future therapies, in particular the domains of gait suggested by Rehman et al (ie, pace, rhythm, variability, asymmetry, and postural control). ${ }^{17}$ Utility in this, however, will rely on an accepted and standardized consensus to be established. ${ }^{32}$

\section{Episodic Gait Dysfunction}

Episodic gait dysfunction comprises disruptive phenomena affecting gait that occur intermittently in an unpredictable manner; principally comprising festination and freezing of gait (FoG). These manifestations may however vary in severity and frequency at any given time and in contrast to the continuous changes that affect gait, the unpredictability makes the development of adaptive strategies challenging.

\section{Festination}

Festination is defined as a tendency to move forward with increasingly rapid but ever-smaller steps, associated with the center of gravity falling forward over the stepping feet. ${ }^{33}$ This definition encompasses both shorter steps and an increased cadence. Festination is an effort to keep the center of gravity over the feet, despite the forward posture and leaning of the trunk, and individuals often describe feeling as if they are being pushed from behind.

\section{Freezing of Gait}

FoG is defined as an episodic inability to generate effective stepping. ${ }^{34}$ During such episodes, individuals often describe their feet as being glued to the floor, and freezing is commonly precipitated by concurrent attentional demands, narrow environmental spaces, and/or the execution of more complex motor tasks whereby change in locomotion, such as initiation of walking, turning, or reaching a destination triggers an episode. ${ }^{35}$ FoG is associated with festination, such that freezing episodes are often preceded by festinating steps. FoG is a common phenomena, with one study of a large PD cohort recruited from outpatient clinics and patient newsletters (mean Hoehn and Yahr stage 2.63) showing that $72 \%$ had experienced FoG and $46.2 \%$ experienced this on a daily basis. ${ }^{36}$ FoG is strongly linked to disease severity, though does not correlate strongly with bradykinesia or rigidity. ${ }^{37,38}$ A number of theories have been proposed to explain FoG. The threshold model suggests that the breakdown of gait as part of continuous gait dysfunction leads to an accumulation of deficits that overcomes a threshold, after which freezing occurs. ${ }^{39}$ The interference model involves excessive compensatory reliance on cognitive processing resources that leads to overactivation of the substantia nigra and inhibition of the PPN, causing freezing. ${ }^{40,41}$ A cognitive model has been suggested, based on the links to freezing and cognitive function, ${ }^{42}$ with similar overreliance on cognitive resources.

Based on our further understanding of brain-structure connectivity, these concepts can be increasingly attributed to neural correlates. Loss of striatal disinhibition in gait effector regions, such as the midbrain, may be responsible for mediating FoG episodes. ${ }^{43}$ Here, release of tonic 
inhibition from basal ganglia nuclei, including the globus pallidus interna (GPi) and substantia nigra from the degenerative striatum, is temporarily lost, leading to the episode. Additionally, ineffective processing of proprioceptive afferent inputs and vestibulocerebellar activity have been proposed to contribute to the network failure that leads to FoG. ${ }^{44}$ The complex, connection-dependent nature of brain function means that FoG is likely multifactorial, with numerous dysfunctional processes contributing.

\section{Key Associations with Gait Dysfunction in PD}

\section{Structural Imaging}

Changes in brain structure have been shown to correlate with the risk or extent of gait dysfunction in PD. Loss of microstructural integrity can be seen in PPN in patients who go on to develop a PIGD phenotype, even in early disease stages, ${ }^{45}$ as with the finding of relatively lower signaling in the caudate nuclei on dopamine-transporter radioligand imaging. ${ }^{46}$ Disproportionate loss of neuromelanin in the substantia nigra is also seen on MRI in PIGD in comparison to tremor-predominant phenotypes. ${ }^{47}$ Patients with FoG have been shown to have decreased surface area of the right parietal cortex compared to nonFoG patients, as well as a volume of white matter involving the right temporal bundle, cingulate gyrus, and corpus callosum. ${ }^{48}$ White-matter changes have increasingly been considered to be associated with gait dysfunction in PD, with relative deterioration of callosal fibres being demonstrated in patients with PIGD versus those without. ${ }^{49}$

\section{Functional Imaging}

Functional MRI (fMRI) may demonstrate utility in showing consequences of structural abnormalities ${ }^{50}$ or detecting change of an order too small to be detected by structural imaging techniques. Studies in patients with FoG have shown reduced resting-state functional connectivity between frontal and occipital networks (correlating with extent of FoG), ${ }^{51}$ as well as between the supplementary motor area and MLR. ${ }^{52}$ Lower relative levels of spontaneous activity have been shown in patients with FoG compared to those without on fMRI in diffuse brain structures, including the anterior cingulate, inferior parietal, superior frontal, and bilateral cerebellar regions. ${ }^{53}$ These findings suggest that global brain dysfunction and loss of connectivity is implicated in the process of FoG. fMRI in FoG patients has been assessed during numerous task- based studies. Imagined motor tasks increase subcortical activity in the MLR, correlating with the severity of $\mathrm{FoG}^{54}$ as well as in other areas, including the cerebellum. ${ }^{55}$ Although an overall effect on brain function is consistently seen, interstudy variability based on differing methodological approaches is a challenge in this area, as frequently seen with fMRI studies. Consistent replication of these functional variations will help support these findings and their link to gait dysfunction.

\section{Neurophysiological Correlates}

Neurophysiological techniques, such as electroencephalography, have been used to examine the dynamic function of the brain during gait-disturbance episodes, such as FoG. Persistent functional abnormality is suggested by the higher resting $\beta$ oscillations seen in subthalamic regions in subjects with FoG than those without FoG, ${ }^{56}$ while greater $\alpha$ rhythms have been demonstrated during periods of freezing. ${ }^{57}$ Event-related potentials, such as the physiological P300 wave related to attention and subsequent decision-making, have been shown to have prolonged latency in $\mathrm{PD}$, in particular when walking relative to sitting. ${ }^{58}$ The lateralized readiness potential (LRP; a premotor potential preceding conscious movement) has also been shown to differ in individuals prone to FoG, with the LRP occurring earlier and with greater amplitude. ${ }^{59}$ Paradigms in which subjects are given dualtask loading allow us to explore variations in attentional mechanisms. The LRP has been shown to be longer while stepping in place versus sitting and during the completion of a task in individuals with FoG, with a reduction in N200 potential (associated with cognitive conflict processing). ${ }^{60}$

\section{Biomarkers}

A multitude of biomarkers are under assessment in PD with the aim of developing a quantitative measure for diagnosis and disease progression. A number of studies have looked at cerebrospinal fluid biomarkers of neurodegeneration and their relationship to gait dysfunction. Low $\mathrm{A} \beta_{42}$ levels have been shown to correlate with progressive deterioration in gait parameters, ${ }^{61}$ as well as varying between the PIGD and tremor-predominant phenotypes, ${ }^{62,63}$ although these findings have not been replicated in other studies. ${ }^{46,64}$ Low $\mathrm{A} \beta_{42}$ has also been associated with risk of FoG. ${ }^{46}$ Cerebrospinal fluid levels of $\alpha$-synuclein and $p-\tau_{181}$ have shown a variable picture: no difference was detected when directly examining gait 
variables, but lower levels were seen based on categorization in an overall PIGD phenotype. Variations between these studies may be explained by differing methods of statistical analysis and modest associations; however, these studies suggest that amyloid may have more of a role in gait disturbance than previously appreciated. Differential patterns of gait abnormality have been seen in PD carriers of the glucocerebrosidase mutation, with decreased armswing velocity and gait symmetry in comparison to nonglucocerebrosidase mutation carrying PD subjects. ${ }^{65}$

\section{Cognition}

Walking is not a wholly automatic motor task, and even in healthy individuals, gait requires some attentional resources. This relationship is explored with studies that utilize dual-task paradigms, whereby walking occurs with a simultaneous task (eg, counting or animal naming), which suggest that maintenance of gait safety and stability may take priority over performance of any additional motor or cognitive task in healthy people. In contrast, dual tasking is altered in PD and has been theorized by some authors to result in a posture second strategy, whereby performance of additional tasks is maintained at the expense of gait stability, ${ }^{66}$ as suggested by the findings of dual-task experiments. Numerous studies have shown that during dual-task conditions, people with PD exhibit increasingly abnormal gait parameters, including reduced stride length, increased interstep variability, gait speed, and left-right asymmetry. ${ }^{67}$ Worsening cognition has also been shown to be associated with slower gait in general outside dual-task paradigms. ${ }^{68}$

These findings have established the importance of the contribution that cognition makes to gait, which fits with the common refrain from patients that stability is compromised when multitasking. While dual-task performance is not a reliable predictor of falls, ${ }^{69}$ dual-task decrements occur in the gait parameters that most strongly correlate with fall risk. ${ }^{70}$ Cognitive impairment is associated with the occurrence of FoG during dual-task experiments, and deficiencies in executive function and cognitive flexibility have been established as risk factors of FoG in general. ${ }^{71}$ This, coupled with the association between anxiety states and fatigue freezing, supports the importance of cognition in gait dysfunction. ${ }^{36}$

\section{Cholinergic Function}

Cholinergic loss is a potent driver of PD-related cognitive dysfunction $^{72}$ and may also have an additional role in development of gait dysfunction. Central cholinergic function is an important modulatory pathway implicated in roles of arousal and attention. Executive function is particularly affected by loss of this type of signaling ${ }^{73}$ which corresponds with the occurrence of both FoG and falls. ${ }^{74}$ Smaller volumes in the basal nucleus of Meynert, the major source of cholinergic signaling to the frontal cortex, correlate with increased step-time variability and shorter step length. ${ }^{75}$ Functional cholinergic activity and its effect on gait has been examined in PD using short-latency afferent inhibition (SAI) techniques, a method measuring the effect of a distal sensory input mediated by cholinergic function in inhibiting a transcranial magnetically stimulated motor potential. Reductions in SAI (and thus cholinergic function) are seen in PD, correlating with increasing gait variability and a slower gait. ${ }^{76} \mathrm{SAI}$ is also reduced disproportionately in individuals with PD who have slower gait during a dual-task activity. ${ }^{77}$ Finally, the pharmacological potentiation of cholinergic signaling in PD improves gait parameters and fall rate. ${ }^{78}$

Deficiencies in cholinergic signaling have been discovered in non-cortical brain areas, thus implicating pathways directly mediating gait, rather than just cognitive processing. Loss of cholinergic neurons in the PPN is seen in both PD and progressive supranuclear palsy on postmortem tissue, and extent of loss correlates with stage of disease. ${ }^{79,80}$ Loss of PPN cholinergic function has an effect independent from the cognitive influence of dysfunctional frontal cholinergic signaling: individuals with the progressive supranuclear palsy parkinsonism variant, a condition with a greater fall risk, do not experience the effects on executive function as in idiopathic PD, and yet have lower levels of cholinergic activity in the PPN. ${ }^{81}$ Radiolabeled imaging studies assessing acetylcholinesterase levels (a correlate of acetylcholine function) also suggest that people with PD who fall have lower levels of PPN cholinergic activity connecting to the thalamus than non-fallers with $\mathrm{PD} .{ }^{74,82,83}$

\section{Correlation with Nonmotor Symptoms}

Subtypes of PD where gait dysfunction (PIGD) or FoG are more frequently seen can demonstrate different profiles of nonmotor symptoms. Autonomic dysfunction, including bladder and bowel symptoms and orthostatic hypotension, have been shown to occur more frequently in individuals with PIGD. ${ }^{84}$ Additionally, objective measures of autonomic function (sympathetic skin response) correlate with the PIGD phenotype. Excessive somnolence has 
been associated with FoG. ${ }^{85}$ The caveat behind all these findings is that these associations may simply arise simultaneously due to advancing disease stage, where both autonomic symptoms and gait dysfunction tend to be more common. On the contrary, RBD is also associated with abnormalities of gait parameters, such as step cadence, length, and risk of freezing episodes ${ }^{86}$ a nonmotor phenomena that frequently occurs as a prodromal symptom. The presence of RBD also predicts development of a less favorable phenotype with increased frequency of falls and less response to levodopa. ${ }^{87}$ This corresponding link likely arises from a common effect on such centers as the MLR that mediate atonia during REM sleep, as well as gait. $^{88}$

A varying relationship has been seen with regard to anxiety and affect on gait. In a study where a PD cohort was split across the median into low- and high-anxiety groups, gait parameters were disrupted (step length and time variability) in the high-anxiety group. ${ }^{89}$ Anxiety was a predictor of FoG in another study, ${ }^{90}$ but another did not reach significance. ${ }^{85}$ The effect on anxiety on FoG and gait dysfunction is complex. Anxiety may commandeer cognitive resources used to compensate for gait, but may also be a symptom of the pattern of aberrant processing that occurs from the common neurodegenerative process. Fear of falling may also worsen the situation, leading to a vicious cycle.

Increasing appreciation of phenotyping that includes nonmotor features rather than the motor picture alone may improve our ability to understand the occurrence of gait dysfunction and its potential shared mechanisms, ${ }^{91}$ of which cholinergic dysfunction is critical. With this perspective, PD should be considered in the context of the often-extensive and multifaceted symptom profile that reflects progression of disease as a manifestation of wholebrain pathology.

\section{Assessment and Measurement of Gait}

Assessment of gait is an important factor in making a diagnosis of PD, as well as monitoring the consequences of disease progression. Historically, this has relied on observation of phenomenology, which is subjective in nature and dependent on experience. Simple measures can be taken, such as timing along a dedicated $10 \mathrm{~m}$ walkway or historical analysis of the footprint signature on marked paper. Video recording can also be used for further assessment or comparison with subsequent observations. However, assessment of gait is complicated by the influence of numerous factors: the environment, current phase of dopaminergic dosing, cognitive and emotional loading, and the impact of any comorbidities that may impact ambulation, such as peripheral neuropathy or musculoskeletal disorders. Falls should be inquired about at each clinical encounter, understanding that the incidence of falls increases with progressive disease staging ${ }^{92}$ and may represent the onset of postural instability, which might not otherwise have been volunteered. This allows the timely application of interventions to assist in fall prevention and instigation of measures, such as optimization of bone health, to mitigate the risk from falls that do occur.

\section{Self-Report and Semiquantitative Scales}

Patient-reported assessment of gait represents the simplest method of gaining information; however, this can be dynamic and difficult to capture accurately over time. Diaries are used in research and clinical settings, but often focus on current medication state (on or off) or the presence of dyskinesia. These can be useful for quantifying the extent of FoG, but struggle to capture this when episodes are very frequent or brief and/or where cognitive impairment coexists. $^{93}$ Self-assessment questionnaires tend to assess the overall impact of gait, such as perception of mobility and occurrence of falls, rather than being able to delineate specific parameters of gait dysfunction. Additionally, self-reported measures have been shown to be unreliable, with discrepancies between patient-reported outcomes and clinician assessment that become more marked with increasing frailty. ${ }^{94,95}$

The Movement Disorder Society Unified Parkinson's Disease Rating Scale (MDS-UPDRS) has become the standard for comprehensive objective assessment of the extent of symptom burden in PD. This is widely used in research and can be used in clinical practice, usually limited by the time needed to complete the assessment. The MDS-UPDRS contains separate scoring entities for FoG, balance, falls, each utilizing a five-point Likert scale assessed by the patient, as well as clinician-determined assessment, such as response to the retropulsion test. The latter can be variable in its execution, introducing subjectivity, and does not correlate strongly with degree of actual postural instability. ${ }^{96}$ Overall MDS-UPDRS scores likely does not adequately reflect gait performance within its overall assessment of disease severity, particularly in relation to other specific scoring systems of gait and balance. ${ }^{97}$ These include the Berg Balance Scale and timed up-and- 
go test, not specific to PD but also widely used in research in interventional studies aimed at gait and falls that have included this condition. Patient-reported outcomes that are available for FoG specifically include the New Freezing of Gait Questionnaire (NFOG-Q) score, which is widely validated, but does not account for variability in medication fluctuations or the role of provoking stimuli, such as distraction or environmental influences. ${ }^{93}$

\section{Quantitative Gait Measurement}

Measuring parameters of gait dysfunction has been shown to independently identify individuals with PD compared to age-matched controls, constituting a potential biomarker to aid in both diagnosis and monitoring. ${ }^{17}$ Specific characteristic profiles of gait abnormality have also been demonstrated in cognitive syndromes, such as Alzheimer's and Lewy body dementia, suggesting yet further utility in exploring gait profile as a proxy for brain function and its potential use in clinical practice. ${ }^{98}$

Several quantitative measurement techniques are available to generate objective data on gait, ranging from wearable devices to multimodal analyses that constitute the gait laboratory (see Table 1). Instrumented electronic walkways, such as the GaitRite system (CIR Systems), represent a powerful tool for measuring gait over a short section, working by detecting pressure changes in the walkway material. However, this is limited to the length of the walkway device $(10 \mathrm{~m})$. Alternatively, measurement devices can be placed within the shoes of the subject, such as the Clinical Stride Analyzer (B\&L Engineering). These devices have demonstrated ability to differentiate the kinematic abnormalities of gait in PD, but are pragmatically confined to use in the clinical care or research environment. $^{99,100}$ The pinnacle of precision for monitoring gait is the modern gait laboratory. This consists of optoelectric systems that detect movement from markers placed over the body, as well as force-plate triggers and electromyography data. Highly precise, this approach is resource-intensive, taking place in an environment that is markedly artificial. Approaches for integrating comprehensive measuring technologies into a more representative environment are being explored. ${ }^{102}$ The importance of taking measurements in a natural, unsupervised environment should be appreciated, as measured parameters have been shown to significantly vary dependent on the nature of the environment in which a parameter is assessed (ie, supervised versus unsupervised). ${ }^{103}$ For this reason, wearable technologies will likely represent the future direction of gait assessment, encompassing the benefit of their ability to take readings in a natural environment with overall cost-effectiveness.

\section{Wearable Devices and Machine Learning}

Wearable devices allow greater flexibility of use, in particular by generating data relevant to the subject's own environment. Inertia-based accelerometry devices are emerging as realistic clinical tools, with this technology already widely adopted in consumer electronics, such as smartphones. Not only has this improved the affordability of such technology but it has also opened up the potential for self-monitoring by patients with their own devices, conceptually representing a digital biomarker for disease progression. ${ }^{101}$ Many scientifically calibrated wearable accelerometry devices are available on the market and have demonstrated the ability to capture parameters of gait, such as stride length, gait speed, and cadence, ${ }^{99}$ with close agreement for similar variables captured with static systems, such as GaitRite. Wearable accelerometry devices have also been useful for assessing FoG. This technique demonstrates best utility in detecting intermediate and prolonged episodes, but has greater difficulty with very short episodes of freezing $(<1$ second). Wearable accelerometry technology can also provide information about overall movement, rather than specific gait metrics. A greater amount of movement may suggest improved confidence with mobility, suggesting a particular intervention may have been beneficial with this outcome measure and thus higher confidence from improved gait stability.

An important factor from here is to achieve consensus on the key gait parameters that correlate with meaningful outcomes for patients. Adopting standardized approaches to those that link research outcomes, such as gait laboratory data, to clinically applicable methods will be crucial, particularly as we enter the era of disease-modifying treatment. Machine-learning techniques have been assessed to assist in processing this type of data, and have the ability to differentiate controls from PD cases, as well as different progressive stages of the condition. ${ }^{104}$ AUC values of $0.76-0.90$ using wearable devices have been obtained, ${ }^{105}$ with particular correlation at earlier PD stages, further reinforcing the potential of gait assessment as an objective biomarker. Advanced gait-assessment techniques processed in this way are also able to predict in which patients FoG may arise based on gait parameters, allowing therapies to be targeted early. $^{106}$ 
Table I Methods of gait assessment and the realistic utility of each in clinical practice

\begin{tabular}{|c|c|c|}
\hline Method & Description & Key points \\
\hline \multicolumn{3}{|l|}{ Subjective } \\
\hline Clinical observation & $\begin{array}{l}\text { Clinically trained personnel assess gait } \\
\text { based on appearance } \\
\text { Can utilize a standardized walkway (eg, } \\
\text { measured corridor) }\end{array}$ & $\begin{array}{l}\text { - Subjective and highly dependent on clinical experience } \\
\text { - No associated cost and time-efficient }\end{array}$ \\
\hline $\begin{array}{l}\text { Self-assessment } \\
\text { - Patient diary } \\
\text { - FOG Questionnaire }\end{array}$ & $\begin{array}{l}\text { Patient completes diary of relevant } \\
\text { events, such as FoG or falls } \\
\text { Completion of questionnaire } \\
\text { concerning recent experience of FoG }\end{array}$ & $\begin{array}{l}\text { - Outcomes relevant to patient } \\
\text { - Diaries reliant on gait outcomes (eg, falls) make it difficult to } \\
\text { document quality of gait } \\
\text { - Challenging when frequent/short events or where cognitive } \\
\text { impairment an issue } \\
\text { - Prone to recall bias } \\
\text { - Cost-effective, but can be burdensome for patients }\end{array}$ \\
\hline \multicolumn{3}{|l|}{ Objective } \\
\hline $\begin{array}{l}\text { Functional assessment scale } \\
\text { - Timed up and go } \\
\text { - Berg balance score }\end{array}$ & $\begin{array}{l}\text { Health-care professional assists patient } \\
\text { in completing standardized assessment, } \\
\text { providing score }\end{array}$ & $\begin{array}{l}\text { - Correlates extensively with current literature } \\
\text { - Cost-effective } \\
\text { - Reliant on staff training with scale and degree of subjectivity in } \\
\text { assessment rating with Berg balance score }\end{array}$ \\
\hline $\begin{array}{l}\text { Foot-switch devices, } \\
\text { - eg, Clinical Stride Analyzer } \\
\text { (B\&L Engineering) }\end{array}$ & $\begin{array}{l}\text { Wired insole devices inserted into each } \\
\text { shoe, measuring pattern of contact/ } \\
\text { pressure to assess gait cycle }\end{array}$ & $\begin{array}{l}\text { - Provides objective measurements of gait parameters } \\
\text { - Different insoles required for different shoe sizes } \\
\text { - Relatively cumbersome and time-consuming to set up }\end{array}$ \\
\hline $\begin{array}{l}\text { Wearable accelerometer } \\
\text { devices }\end{array}$ & $\begin{array}{l}\text { Device with inertial movement sensor, } \\
\text { worn for desired period of assessment } \\
\text { - Can be combined with global } \\
\text { positioning system (GPS) data }\end{array}$ & $\begin{array}{l}\text { - Objective with wide range of gait parameters measurable } \\
\text { - Easy to provide to patient to assess in their own environment, } \\
\text { possible to measure "life sphere" with GPS } \\
\text { - Increasingly cost-effective and incorporated into modern devices, } \\
\text { such as smartphones } \\
\text { - Varying levels of sophistication, with increasing utility comes } \\
\text { increasing size and extent (eg, single wristwatch measuring gait speed } \\
\text { versus multilimb setup measuring full gait cycle) }\end{array}$ \\
\hline $\begin{array}{l}\text { Instrumented walkway, } \\
\text { • eg, GaitRite (CIR Systems) }\end{array}$ & $\begin{array}{l}\text { Sensor walkway measuring contact } \\
\text { with feet to assess gait cycle }\end{array}$ & $\begin{array}{l}\text { - Objective measurement of gait cycle } \\
\text { - Expensive } \\
\text { - Limited to clinical environment and by length of walkway } \\
\text { (approximately } 10 \mathrm{~m} \text { ) }\end{array}$ \\
\hline Laboratory gait analysis & $\begin{array}{l}\text { Dedicated environment containing } \\
\text { sophisticated methods for quantifying } \\
\text { gait parameters (optical, contact } \\
\text { pressure, and electromyogram } \\
\text { measurements) }\end{array}$ & $\begin{array}{l}\text { - Precise and sophisticated assessment of gait } \\
\text { - Highly expensive } \\
\text { - Not realistic to incorporate into clinical spaces } \\
\text { - Assesses patient in highly artificial environment }\end{array}$ \\
\hline
\end{tabular}

\section{Management of Gait Dysfunction in Parkinson's Disease}

The management of gait dysfunction in PD remains symptomatic, while disease-modifying treatments for PD are lacking. The mainstay of therapy, dopaminergic replacement, is primarily addressed at improving symptoms of tremor, rigidity, and bradykinesia, in particular classified as being in an off or on state. Addressing these symptoms and enhancing on time likely contributes to gait function; however increasing effort is being invested in gait stability and subsequent falls as an outcome measure, leading to the evaluation of specific interventions to improve these symptoms. 
Mitigating the effects of falls as they occur is a highly important consideration. Major fractures can be devastating life events that lead to a permanent decompensation in function and loss of independence, and thus measures to prevent falls and also optimize bone health are vital. People with PD are at higher risk of fracture for each fall they experience, having lower bone-mineral density than similarly aged controls. ${ }^{107}$ The assessment and management of bone health is outside the scope of this article and has been addressed elsewhere. ${ }^{108}$ Other considerations should fit the patient's lifestyle. Exercise is highly beneficial in $\mathrm{PD}$, and putatively may have a disease-modifying effect; ${ }^{109}$ however, the potential for an increased chance of falling should be appreciated, and mitigating strategies, such as the use of hip protectors, can be considered on an individual basis.

\section{Physical Therapy and Training}

Physical therapy interventions have been utilized in the PD population with an aim to increase strength, balance, and compensatory strategies. Randomized controlled trials undertaken on strategies to reduce falls in people with PD have been multifaceted and included resistance training, aerobic exercise, and movement and balance strategies. These approaches are designed to improve gait dysfunction, address muscle weakness and loss of power, reduce symptom severity, and improve balance.

External cueing strategies using auditory, visual, or sensory paradigms have shown success in improving continuous gait impairments by improving stride length and cadence. ${ }^{110}$ Utilizing visual cueing strategies allows the bypassing of deficient gait-control pathways, instead recruiting cortical structures linked with attention and voluntary control of movement to compensate. Promotion of anticipatory eye movements via visual cueing strategies has also been shown to improve gait speed and reduce falls in PD. ${ }^{111}$ These strategies likely lead to recruitment of collateral neural pathways, and may explain the improvement seen with reverse (backward) gait training on gait speed and cadence compared to forward walking. ${ }^{112}$

Complex motor-strategy training can be used to improve dual-task performance, and involves a combination of gait and cognitive tasks that encourage recruitment of compensatory pathways. ${ }^{113}$ This has been shown to be effective at increasing stride length, cadence, and gait speed in people with PD. ${ }^{114}$
Cognitive training as an intervention for gait dysfunction consists of practicing tasks to improve areas likely to impact FoG, such as inhibitory control, attentional setshifting, working memory, processing speed, and visuospatial skills, ${ }^{115}$ with compensatory effects observed on gait from improvements in these domains. ${ }^{116}$ Worsening cognition (as measured by the Mini-Mental State Examination) correlates with FoG, and individual visuospatial ability has been shown to distinguish between those with and without freezing. ${ }^{117}$ In terms of rehabilitation, targeting both the motor aspect of PD and the cognitive can lead to improvements in symptoms, ${ }^{115}$ although these do not have to be undertaken simultaneously to be effective. ${ }^{118}$

Walton et al assessed the effect of cognitive training versus control on gait parameters measured by timed up and go, ${ }^{115}$ and found significant improvement in FoG. In their systematic review, Delgado-Alvarado el $\mathrm{al}^{119}$ noted that cognitive training had a long-lasting effect on FoG based on the nine studies assessed.

Resistance and aerobic exercise can also be useful in improving gait kinematics. Cycling has been shown to be as effective as treadmill walking for improvements in gait speed, step length, and cadence, suggesting that at least some aspect of gait dysfunction in people with PD may be partly due to generic deconditioning. ${ }^{120}$ Resistance training improves strength and power, which may also play a part in gait dysfunction in this population, ${ }^{121-123}$ and can also be used to improve continuous gait-dysfunction symptoms; however, evidence for this remains limited. ${ }^{124,125}$

Organized physical activity programs, such as Lee Silverman Voice Treatment(LVST -Big), have been shown to be effective at increasing stride length and improving timed up-and-go times, but the general effect of face-to-face input with a physiotherapist may be a confounding factor. ${ }^{126,127}$

Fear of falling has been associated with loss of independence and reduced quality of life, ${ }^{128}$ and there is evidence to suggest a correlation between fear of falling and gait disturbances. ${ }^{129}$ The link between anxiety and FoG in PD has also been investigated to establish whether anxiety exacerbates FoG or whether the opposite occurs. ${ }^{129,130}$ Interventions that target solely nonmotor (such as anxiety) or motor symptoms may not be optimal, given the multifactorial interactions among psychological and physical aspects of PD. 


\section{Medical Devices}

New technologies are facilitating novel approaches to physical therapies in PD and helping to reduce burden on health-care services. An example of this is the laser shoe, which allows ongoing support at home beyond the inperson consultation. ${ }^{131,132}$ Such interventions are adaptable and can be individualized to help reduce dependence on cueing, although the benefits appear to diminish over time with decreasing cognitive ability. ${ }^{132}$ The benefit of physical therapies may be further enhanced through the use of robot-assisted devices, which have been shown to provide a greater improvement in outcomes than traditional gait training alone. ${ }^{133}$ The use of virtual-reality training methods has also been examined in a number of studies, overall showing a beneficial effect. ${ }^{134}$

In general, the most highly studied devices have tended to address FoG, and can be divided into three categories: those providing auditory stimulation, visual cueing, and somatosensory electrical stimulation. Auditory devices that provide a cueing signal when FoG is detected have been investigated in small samples, ${ }^{135-137}$ but with few data to prove their effectiveness in the long term. Visual cueing techniques, such as laser canes, ${ }^{138,139}$ checkerboard projections, ${ }^{140}$ laser shoes, ${ }^{131}$ and smartglasses,${ }^{141}$ have all been shown to reduce instances of FoG in both on and off states.

Devices that provide somatosensory electrical stimulation have also been developed to alleviate FoG. McCandless et al investigated the effect of visual, auditory, and somatosensory cues in people with PD using a BodyBeat pulsing metronome (Peterson ElectroMusical Products), ${ }^{142}$ and found that the vibration was more effective than the control (no device) at improving gait parameters, although the visual cueing devices were more effective than both auditory and somatosensory devices. Other devices, such as the CueStim and VibroGait, ${ }^{143}$ have shown positive effects in reducing FoG. ${ }^{144,145}$

While physical therapies have been shown to be effective, resources are often scarce within health-care systems, and treatment requires long-term adherence to see continuation of the benefits. ${ }^{146}$ This represents a significant challenge to those responsible for providing physical therapy to people with PD. ${ }^{147}$ Virtual and wearable technologies represent an ideal way of improving access and duration of therapy, allowing ongoing and customized use at the patient's convenience.

\section{Pharmacological \\ Effect of Dopaminergic Therapies on Gait Dysfunction}

Pharmacological management in PD comprises the mainstay of therapy, namely enhancement of dopaminergic neurotransmitter function through the use of dopamine replacement, receptor agonism, or the alteration of dopamine handling in the synaptic cleft. The main aim of dopamine replacement is to improve rigidity and bradykinesia with an effect on tremor at higher doses. The effect of dopaminergic therapy on gait dysfunction and consequential falls is less straightforward. A number of studies have assessed the quantitative parameters of gait, with mixed results. Consistent improvement in gait velocity and stride length have been seen across studies while in the on state using levodopa compared to the off state; ${ }^{148}$ however, stride duration and cadence have been shown to be unaffected, except in a single study. ${ }^{149}$ A smaller number of studies have looked at the positive effect on arm swing while in the on state, ${ }^{149,150}$ as well truncal movement. Improvements in turning and gait adaptability have also been seen. FoG severity is improved while in the on state, ${ }^{82}$ although a limited subset of people can experience worsening FoG during "on" periods, ${ }^{9,148}$ highlighting the complex role of dopaminergic signaling in PD that is beyond a mere deficiency in neurotransmitter levels. Dopamine agonists have been examined to a lesser extent, but have been shown to improve overall gait parameters, and in one study were superior to levodopa. ${ }^{152}$ Monoamine oxidase $\mathrm{B}$ inhibitors have demonstrated mixed results, with older studies intended to assess effects on disease progression suggesting a lower risk of FoG. This, however, has not been observed in newer studies. ${ }^{148}$ Catechol-O-methyltransferase inhibitors have limited evidence for improving gait parameters, likely caused by improving "on" time.

Many studies examining the role of dopaminergic therapies have assessed this effect over just a short period (such as on and off medication within a single day). The effect of optimized dopaminergic therapy and long-term influence on the development of gait dysfunction is unclear, although intuitively maintaining the on period for as long as possible should decrease the risk of consequences, such as falls. However, by affording individuals improved movement, this paradoxically increases their exposure to fall risk. This may account for the reduction in fall risk seen in late disease, with mobility 
profoundly restricted and independent walking precluded. The fall rate thus likely peaks around Hoehn and Yahr stage III disease. Where a concurrent decrease in the on state is seen also seen for interventions, ${ }^{153}$ it is difficult to unpick whether any parallel effect on gait is intrinsically linked. Regardless, responsive optimization of dopaminergic medication over the course of an individual's journey with PD is likely beneficial in ameliorating gait dysfunction.

\section{Cholinesterase Inhibitors}

Cholinesterase inhibitors (ACEi) have an established role in various neurodegenerative diseases, where they are postulated to improve cognition by enhancing cholinergic signaling through increasing acetylcholine availability for synaptic transmission. These have been examined in several studies with the intention of improving gait performance in $\mathrm{PD}$, the rationale being to account for the deficit in cholinergic signaling that may impact on gait as, including through cognitive and attentional mechanisms. This modality of treatment holds some of the strongest evidence for an effect on gait dysfunction out of all pharmacological approaches. Studies have assessed donepezil, rivastigmine, and galantamine in order of decreasing frequency and range from earlier studies where falls were counted as part of adverse-effect monitoring to later studies where gait and balance parameters were primary outcomes. A majority of studies designed to assess gait dysfunction demonstrated a positive effect of ACEi treatment. The most consistently reported outcome is a decrease in the occurrence of falls in studies designed to assess this parameter, ${ }^{78,154-159}$ although disagreeing with older studies, where these were secondarily recorded as adverse outcomes. ${ }^{160-162}$ This discrepancy likely arises from methodological differences. Mixed results in quantitative gait parameters have been observed (see Table 2).

Care should also be taken with people with PD to ensure they are not exposed to unnecessary cholinergic blockade, such as through antimuscarinic medications for the bladder, and other sources, such as amitriptyline. These all exert a negative effect on cholinergic signaling, and are well recognized to detrimentally affect gait and cognition. ${ }^{163}$

\section{NMDA Agonists}

NMDA agonists are commonly used in PD in the form of amantadine, chiefly for the purpose of improving the symptoms of dyskinesia when present. This class of medication has been examined for its effect on gait dysfunction, with varying outcomes for FoG when given intravenously. Uncontrolled case series have demonstrated benefit, ${ }^{164,165}$ though several subsequent controlled studies demonstrated no effect. ${ }^{166,167}$ Memantine has also been examined, not demonstrating any effect on gait speed or cadence, but demonstrating a small effect on the UPDRS axial subscore. ${ }^{168}$

\section{Methylphenidate}

Methylphenidate acts as a dopamine-reuptake inhibitor, lending itself to the potential treatment of PD. An early study demonstrated improvement in gait speed, variability, and timed up-and-go times, although it was uncontrolled. ${ }^{169}$ Subsequent randomized control studies have shown mixed results, ${ }^{170-172}$ with variability in the selection of patients being among the confounding issues, suggesting further well-designed trials are needed.

\section{Dalfampridine}

Dalfampridine (4-aminopyridine) is a potassium-channel antagonist and has been tried in a number of neurological conditions, most notably Lambert-Eaton myasthenic syndrome and multiple sclerosis for symptoms of fatigue. A single double-blinded study has examined the effect of dalfampridine on gait dysfunction in PD, following a case report of its potential effect. ${ }^{173}$ This showed no effect on gait parameters that included gait speed and stride length. ${ }^{174}$

\section{Adenosine Antagonists}

The $\mathrm{A}_{2 \mathrm{~A}}$ adenosine receptor has become a target of interest, with the $\mathrm{A}_{2 \mathrm{~A}}$-receptor antagonist istradefylline recently gaining US Food and Drug Administration approval for treating "off" periods in PD. This is the same receptor at which caffeine acts, and a small blinded crossover trial where patients were determined as responders or nonresponders (based on their own global impression of improvement) demonstrated improved FoG with caffeine dosing as determined by FOG-Q response. This improvement disappeared after several months, and could not be reproduced after a washout period. ${ }^{175}$ Two uncontrolled trials specifically examining FoG after treatment with istradefylline have also been undertaken, both showing a significant improvement in FOG-Q scores. Similar assessment of effect on timed up-and-go scores did not reach significance. ${ }^{176}$ Mixed effects on UPDRS part III scores have been shown, with one study demonstrating no effect (although not providing a breakdown of subscores) 
Table 2 Studies examining use of acetylcholinesterase inhibitors and parameters of gait, balance, or occurrence of falls

\begin{tabular}{|c|c|c|c|c|}
\hline & $\begin{array}{l}\text { Study } \\
\text { design }\end{array}$ & Intervention & Population & Findings \\
\hline Stuart et al ${ }^{154}$ & $\begin{array}{l}\text { Randomized, } \\
\text { double-blind, } \\
\text { crossover }\end{array}$ & Donepezil & $\begin{array}{l}\text { Idiopathic Parkinson's } \\
\text { disease }(n=20)\end{array}$ & $\begin{array}{l}\text { Improvement in stride length }(P=0.002) \text { and dual-task } \\
\text { performance (reaction time } P=0.004) \\
\text { Trend for improvement in gait speed and variability did } \\
\text { not reach significance }\end{array}$ \\
\hline Mancini et al ${ }^{155}$ & $\begin{array}{l}\text { Randomized, } \\
\text { double-blind }\end{array}$ & Donepezil & $\begin{array}{l}\text { Idiopathic Parkinson's } \\
\text { disease }(n=45)\end{array}$ & $\begin{array}{l}\text { Trend for improvement in mediolateral sway range (not } \\
\text { significant, skewed by outliers), improvement in } \\
\text { mediolateral sway dispersion }(P=0.004) \\
\text { No change in gait speed or stride-time variability. }\end{array}$ \\
\hline Lauretani et al ${ }^{156}$ & Case report & Donepezil & $\begin{array}{l}\text { Single case, idiopathic } \\
\text { Parkinson's disease }\end{array}$ & Improvement in gait speed, cadence, and stride length \\
\hline Henderson et $\mathrm{al}^{78}$ & $\begin{array}{l}\text { Randomized, } \\
\text { double-blind }\end{array}$ & Rivastigmine & $\begin{array}{l}\text { Idiopathic Parkinson's } \\
\text { disease }(n=\mid 30)\end{array}$ & $\begin{array}{l}\text { Improvement in step-time variability during simple } \\
\text { walking }(P=0.002) \text { and simple dual task }(P=0.045) \\
\text { Improved gait speed }(P=0.003) \text {, controlled leaning } \\
\text { balance score }(P=0.008) \\
\text { Decrease in overall fall rate }(P=0.002) \\
\text { No effect on FoG or step variability with complex dual } \\
\text { task }\end{array}$ \\
\hline Emre et $\mathrm{al}^{160}$ & $\begin{array}{l}\text { Randomized, } \\
\text { open-label }\end{array}$ & Rivastigmine & $\begin{array}{l}\text { Parkinson's disease } \\
\text { dementia }(n=580)\end{array}$ & Adverse-effect data: no significant variation in falls \\
\hline Dubois et $\mathrm{al}^{161}$ & $\begin{array}{l}\text { Randomized, } \\
\text { double-blind }\end{array}$ & Donepezil & $\begin{array}{l}\text { Parkinson's disease } \\
\text { dementia }(n=550)\end{array}$ & $\begin{array}{l}\text { Adverse-effect data: mean falls } 6.2 \text { ( } 5 \mathrm{mg} \text { donepezil), } 5.5 \\
\text { ( } 10 \mathrm{mg} \text { donepezil), and } 5.2 \text { (placebo) - no significant } \\
\text { difference }\end{array}$ \\
\hline Li et al ${ }^{159}$ & $\begin{array}{l}\text { Randomized, } \\
\text { double-blind }\end{array}$ & Rivastigmine & $\begin{array}{l}\text { Idiopathic Parkinson's } \\
\text { disease and Parkinson's } \\
\text { disease dementia }(n=176)\end{array}$ & Decreased incidence of falls $(P<0.0 \mathrm{I})$ \\
\hline Chung et al ${ }^{157}$ & $\begin{array}{l}\text { Randomized } \\
\text { crossover }\end{array}$ & Donepezil & $\begin{array}{l}\text { Idiopathic Parkinson's } \\
\text { disease }(n=23)\end{array}$ & $\begin{array}{l}\text { Decreased incidence of falls }(P<0.05) \\
\text { No improvement in Berg Balance Scale or Balance } \\
\text { Confidence Scale }\end{array}$ \\
\hline Litvinenko et al ${ }^{158}$ & $\begin{array}{l}\text { Open-label, } \\
\text { placebo- } \\
\text { controlled }\end{array}$ & Galantamine & $\begin{array}{l}\text { Parkinson's disease } \\
\text { dementia }(n=4 I)\end{array}$ & $\begin{array}{l}\text { Decreased rate of falls }(P=0.04) \text {, improvement in } \\
\text { freezing }(P=0.03) \text { and gait disturbance }(P=0.04)- \\
\text { UPDRS scores. }\end{array}$ \\
\hline Emre et al ${ }^{162}$ & $\begin{array}{l}\text { Randomized, } \\
\text { double-blind }\end{array}$ & Rivastigmine & $\begin{array}{l}\text { Parkinson's disease } \\
\text { dementia }(n=54 I)\end{array}$ & Adverse-effect data: no significant difference in falls \\
\hline
\end{tabular}

Abbreviation: UPDRS, Unified Parkinson's Disease Rating Scale.

and another demonstrating differences in both overall scores and gait items. ${ }^{177}$ Further studies involving placebo are required to fully assess this benefit.

\section{Neuromodulation Techniques \\ Deep-Brain Stimulation}

Deep-brain stimulation (DBS) has emerged as a commonly used advanced therapy that improves the traditional "cardinal" symptoms of PD (bradykinesia, rigidity, and tremor).
Most commonly, it is used to treat refractory motor fluctuations in PD, particularly for younger individuals in whom surgery is appropriate, routinely targeting the subthalamic nucleus (STN) or GPi. As experience with this technique has developed and our understanding of the pathological processes behind PD has increased, the role of DBS in gait dysfunction has been considered.

STN- and GPi-stimulation studies have both have been shown to have mixed effects on gait parameters. GPi 
stimulation can be associated with a worsening of gait, though a small benefit has been demonstrated in other studies based on UPDRS part III subscores. ${ }^{178}$ STN stimulation has shown varied outcomes, from no improvement to a degree of improvement in such parameters such as FoG (although ineffective in some studies), ${ }^{179}$ as well as a consistent improvement in gait speed. ${ }^{180}$ Improvement in stride length and symmetry have also been seen, with changes present only during application of stimulation. ${ }^{181,182}$ Where benefit has been demonstrated for both stimulation sites, improvement has often beenshort lived. Potential using low versus high frequency (the standard for DBS) stimulation paradigms has been demonstrated, with improvement in FoG seen at $60 \mathrm{~Hz}$ compared to $130 \mathrm{~Hz}{ }^{183}$ This corresponds with an increased understanding of variation in clinical effect with differing frequencies for many forms of neuromodulation.

Interest in the PPN as a target for DBS has arisen from its increasingly revealed role in mediating gait and evidence of gait dysfunction in PD. A recent meta-analysis, including double-blinded studies, showed than PPN stimulation improved FoG frequency and occurrence of falls in both on and off medication states, but may have little benefit for symptoms of bradykinesia, tremor, or rigidity as provided by GPi or STN stimulation. ${ }^{184}$ For this reason, combined stimulation of both traditional DBS targets and the PPN has been considered, with early case series showing improvement in gait parameters. ${ }^{178} \mathrm{~A}$ further target of interest is the substantia nigra, which when stimulated has demonstrated improvements in swing-time asymmetry ${ }^{182}$ and FoG. ${ }^{185,186}$ Further systematic assessment is required in larger trials before this strategy can be adopted more widely.

\section{Spinal Cord Stimulation}

Spinal cord stimulation has been increasingly explored in $\mathrm{PD}$ as a technique to improve gait dysfunction. This modality of treatment may show promise, due to its connective proximity downstream from the PPN, where DBS has been shown to be effective in improving walking function. Several recent clinical trials have been carried out in this area, with stimulation of the spinal cord being undertaken at both cervical and thoracic levels using directly implanted electrodes or transspinal magnetic techniques to deliver stimulation and assessment of stimulation at numerous frequencies. Improvements in gait parameters, such as stride length, velocity, and FoG, have been demonstrated. $^{187,188}$ These studies were heterogeneous in design, and a majority were uncontrolled (with small numbers only in controlled trials).

\section{Transcranial Magnetic Stimulation}

Transcranial magnetic stimulation provides non-invasive stimulation of the cerebral cortex induced by strong, focused electromagnetic fields, and has been examined for its effect on gait dysfunction in numerous studies. ${ }^{189}$ These have involved a number of sites targeted for therapeutic stimulation corresponding to areas postulated to be involved in gait and its dysfunction in PD, including the motor and prefrontal cortices. ${ }^{190,191}$ Multiple frequency patterns have also been examined, and this modality is similarly complicated by a heterogeneity of studies. Considerable difficulty is also posed by generating a believable sham stimulation. Results have been mixed and tended to lack long-term improvement, even after an initial period of response. Encouraging results have been seen in one of the few randomized placebo-controlled trials undertaken for this approach, where FoG (FOG-Q) and timed up-and-go tests were shown to improve with double-coil stimulation of the motor cortex at high frequency. ${ }^{192}$

\section{Transcranial Electric Stimulation}

Transcranial electric stimulation involves the non-invasive application of a current to the scalp via a set of electrodes, and is thought to penetrate the skull and influence neuronal function. This modality has been investigated in PD for gait and balance dysfunction utilizing a range of stimulation paradigms, including direct and alternating current, pulsed and random-noise stimulation. The findings should be interpreted with caution, due to study heterogeneity and methodological challenges in blinding. ${ }^{193}$ A randomized placebo-controlled trial of direct current stimulation (DCS) combined with physical therapy demonstrated a significant improvement in cadence, but not for stride length or timed up-and-go time, and the effects were sustained with DCS compared to physiotherapy alone. However, the small extent of improvement was not felt to be clinically relevant, ${ }^{194}$ an important concept that requires further consideration in a majority of interventional studies on PD. A further placebo-controlled study of DCS for a dual-task assessment showed improved gait speed during the dual task, though not for the single task. ${ }^{195}$ Ongoing systematic study of this treatment paradigm is required to establish its genuine utility. 


\section{Conclusion}

Our understanding of the mechanisms that cause gait dysfunction in PD has evolved substantially over the last few decades. Increasingly, motor symptoms are being seen as being beyond the cardinal features of tremor, bradykinesia, and rigidity. and the association of impaired dopaminergic signaling with disordered walking and balance represent a significant burden on patients. Our ability to assess gait objectively continues to develop and will likely become ever more sophisticated as we move to wearable smart technologies that can be used by patients in their own homes, representing their own real-life environments. This may allow gait to be utilized as a biomarker, sensitive enough for not only the diagnosis of PD but also progression monitoring, important in facilitating the development of disease-modifying treatments.

Physical therapies remain a key feature of optimizing gait function, and the incorporation of new technologies promises to improve the efficacy and reach of treatment. Traditional pharmacotherapy for PD has consisted of enhancing dopaminergic function, and although a direct effect on gait is not clear, optimization of dopaminergic medication likely contributes to improving gait and FoG. Numerous other pharmacological approaches have been considered, with the effect of acetylcholinesterase inhibitors being most promising on outcomes related to gait stability and falls. The effect of DBS using traditional basal ganglia targets suggests that little effect is seen on improving gait; however more promising results have been seen with the advent of stimulation of the PPN: mixed-target stimulation is likely the future of this approach. A number of other neuromodulation approaches have been trialed, including spinal cord stimulation, but evidence in this domain remains limited and results from future controlled trials are required.

\section{Ethics}

Ethics approval was not required for this paper.

\section{Disclosure}

EJH is chief investigator for a UK National Institute of Health Research (NIHR) Health Technology Assessment grant, funding a phase III trial of rivastigmine to prevent falls in Parkinson's disease, and reports a grant from Parkinson's UK during the conduct of the study, personal fees from Luye outside the submitted work, and personal fees and nonfinancial support from Bial, AbbVie, and
Profile outside the submitted work. The authors report no other conflicts of interest in this work.

\section{References}

1. Parkinson's UK. Incidence and Prevalence of Parkinson's in the UK: Results from the Clinical Practice Datalink Summary Report. Parkinson's UK; 2018.

2. Martinez-Martin P, Skorvanek M, Rojo-Abuin JM, et al. Validation study of the hoehn and yahr scale included in the MDS-UPDRS. Mov Disord. 2018;33(4):651-652. doi:10.1002/ mds. 27242

3. Low V, Ben-Shlomo Y, Coward E, et al. Measuring the burden and mortality of hospitalisation in Parkinson's disease: a crosssectional analysis of the English Hospital Episodes Statistics database 2009-2013. Park Relat Disord. 2015;21(5):449-454. doi:10.1016/j.parkreldis.2015.01.017

4. Schrag A, Ben-Shlomo Y, Quinn N. How common are complications of Parkinson's disease? J Neurol. 2002;249(4):419-423. doi: $10.1007 / \mathrm{s} 004150200032$

5. Pouwels S, Bazelier MT, de Boer A, et al. Risk of fracture in patients with Parkinson's disease. Osteoporos Int. 2013;24 (8):2283-2290. doi:10.1007/s00198-013-2300-2

6. Pickering RM, Grimbergen YAM, Rigney U, et al. A metaanalysis of six prospective studies of falling in Parkinson's disease. Mov Disord. 2007;22(13):1892-1900. doi:10.1002/ mds. 21598

7. Mühlenfeld N, Söhling N, Marzi I, et al. Fractures in Parkinson ' s disease: injury patterns, hospitalization, and therapeutic aspects. Eur J Trauma Emerg Surg. 2021;47(2):573-580. doi:10.1007/ s00068-019-01240-z

8. Abou L, Aditya A, Fliflet A, Titing D, Rice L. Effectiveness of physical therapy interventions in reducing fear of falling among individuals with neurologic diseases: a systematic review and meta-analysis. Arch Phys Med Rehabil. 2021;102(1):132-154. doi:10.1016/j.apmr.2020.06.025

9. Espay AJ, Fasano A, van Nuenen BFL, et al. 'On' state freezing of gait in Parkinson disease: a paradoxical levodopa-induced complication. Neurology. 2012;78(7):454-457. doi:10.1212/ WNL.0b013e3182477ec0

10. Yang JF, Stephens MJ, Vishram R. Infant stepping: a method to study the sensory control of human walking. J Physiol. 1998;507 (3):927-937. doi:10.1111/j.1469-7793.1998.927bs.x

11. Takakusaki K, Habaguchi T, Saitoh K, Kohyama J. Changes in the excitability of hindlimb motoneurons during muscular atonia induced by stimulating the pedunculopontine tegmental nucleus in cats. Neuroscience. 2004;124(2):467-480. doi:10.1016/j. neuroscience.2003.12.016

12. Takakusaki K. Neurophysiology of gait: from the spinal cord to the frontal lobe basic framework of locomotor control spinal locomotor network generates basic locomotor pattern. Mov Disord. 2013;28(11):1483-1491. doi:10.1002/mds.25669

13. Duysens J, Nonnekes J. Parkinson's kinesia paradoxa is not a paradox. Mov Disord. 2021;36(5):1115-1118. doi:10.1002/ mds. 28550

14. Snijders AH, Takakusaki K, Debu B, et al. Physiology of freezing of gait. Ann Neurol. 2016;80(5):644-659. doi:10.1002/ana.24778

15. Kish S, Shannak K, Hornykiewicz O. Uneven pattern of dopamine loss in the striatum of patients with idiopathic Parkinson's disease. $N$ Engl J Med. 1988;318(14):876/880. doi:10.1056/ NEJM198804073181402

16. Giladi N, Horak F, Hausdorff JM. Classification of gait disturbances: distinguishing between continuous and episodic changes. Mov. Disord. 28, 1469-73 (2013). 
17. Rehman RZU, Del Din S, Guan Y, et al. Selecting clinically relevant gait characteristics for classification of early parkinson's disease: a comprehensive machine learning approach. Sci Rep. 2019;9(1):1-12. doi:10.1038/s41598-019-53656-7

18. Hausdorff JM. Gait dynamics in Parkinson's disease: common and distinct behavior among stride length, gait variability, and fractal-like scaling. Chaos. 2009;19(2):26113. doi:10.1063/ 1.3147408

19. Hausdorff JM, Cudkowicz ME, Firtion R, Wei JY, Goldberger AL. Gait variability and basal ganglia disorders: stride-to-stride variations of gait cycle timing in Parkinson's disease and Huntington's disease. Mov Disord. 1998;13(3):428-437. doi: $10.1002 / \mathrm{mds} .870130310$

20. Morris ME, Iansek R, Matyas TA, Summers JJ. The pathogenesis of gait hypokinesia in parkinson's disease. Brain. 1994;117 (5):1169-1181. doi:10.1093/brain/117.5.1169

21. Scherder E, Eggermont L, Swaab D, et al. Gait in ageing and associated dementias; its relationship with cognition. Neurosci Biobehav Rev. 2007;31(4):485-497. doi:10.1016/j. neubiorev.2006.11.007

22. Montero-Odasso M, Muir SW, Hall M, et al. Gait variability is associated with frailty in community-dwelling older adults. $J$ Gerontol Ser A Biol Sci Med Sci. 2011;66(A):568-576. doi:10.1093/gerona/glr007

23. Blin O, Ferrandez AM, Serratrice G. Quantitative analysis of gait in Parkinson patients: increased variability of stride length. J Neurol Sci. 1990;98(1):91-97. doi:10.1016/0022-510X(90) 90184-O

24. Schaafsma JD, Giladi N, Balash Y, et al. Gait dynamics in Parkinson's disease: relationship to Parkinsonian features, falls and response to levodopa. J Neurol Sci. 2003;212(1-2):47-53. doi:10.1016/S0022-510X(03)00104-7

25. Plotnik M, Giladi N, Hausdorff JM. A new measure for quantifying the bilateral coordination of human gait: effects of aging and Parkinson's disease. Exp Brain Res. 2007;181(4):561-570. doi:10.1007/s00221-007-0955-7

26. Bogen B, Aaslund MK, Ranhoff AH, Moe-Nilssen R. Two-year changes in gait variability in community-living older adults. Gait Posture. 2019;72:142-147. doi:10.1016/j.gaitpost.2019.06.005

27. Afsar O, Tirnakli U, Marwan N. Recurrence quantification analysis at work: quasi-periodicity based interpretation of gait force profiles for patients with Parkinson disease. Sci Rep. 2018;8 (1):1-12. doi:10.1038/s41598-018-27369-2

28. Zanardi APJ, da Silva ES, Costa RR, et al. Gait parameters of Parkinson's disease compared with healthy controls: a systematic review and meta-analysis. Sci Rep. 2021;11(1):1-13. doi:10.1038/ s41598-020-80768-2

29. Mcdade EM, Boot BP, Christianson TJH, et al. Subtle gait changes in patients with REM sleep behavior disorder. Mov Disord. 2013;28(13):1847-1853. doi:10.1002/mds.25653

30. Lord S, Galna B, Yarnall AJ, et al. Predicting first fall in newly diagnosed Parkinson's disease: insights from a fall-naïve cohort. Mov Disord. 2016;31(12):1829-1836. doi:10.1002/ mds. 26742

31. Nyström H, Nordström A, Nordström P, de Craen AJM. Risk of injurious fall and hip fracture up to $26 \mathrm{y}$ before the diagnosis of parkinson disease: nested case-control studies in a nationwide cohort. PLoS Med. 2016;13(2):1-14. doi:10.1371/journal. pmed.1001954

32. Lord S, Galna B, Rochester L. Moving forward on gait measurement: toward a more refined approach. Mov Disord. 2013;28 (11):1534-1543. doi:10.1002/mds.25545

33. Nutt JG, Bloem BR, Giladi N, Hallett M, Horak FB, Nieuwboer A. Freezing of gait: moving forward on a mysterious clinical phenomenon. Lancet Neurol. 2011;10 (8):734-744. doi:10.1016/S1474-4422(11)70143-0
34. Giladi N, Nieuwboer A. Understanding and treating freezing of gait in Parkinsonism, proposed working definition, and setting the stage. Mov Disord. 2008;23(S2):423-425. doi:10.1002/mds.21927

35. Schaafsma JD, Balash Y, Gurevich T, et al. Characterization of freezing of gait subtypes and the response of each to levodopa in Parkinson's disease. Eur J Neurol. 2003;10(4):391-398. doi:10.1046/j.1468-1331.2003.00611.x

36. Rahman S, Griffin H, Quinn N, Jahanshahi M. The factors that induce or overcome freezing of gait in Parkinson's disease. Behav Neurol. 2008;19(3):127-136. doi:10.1155/2008/456298

37. Bartels AL, Balash Y, Gurevich T, et al. Relationship between freezing of gait (FOG) and other features of Parkinson's: FOG is not correlated with bradykinesia. J Clin Neurosci. 2003;10 (5):584-588. doi:10.1016/S0967-5868(03)00192-9

38. Macht M, Kaussner Y, Möller JC, et al. Predictors of freezing in Parkinson's disease: a survey of 6620 patients. Mov Disord. 2007;22(7):953-956. doi:10.1002/mds.21458

39. Plotnik M, Giladi N, Hausdorff JM. Is freezing of gait in Parkinson's disease a result of multiple gait impairments? Implications for treatment. Parkinson's Dis. 2012;2012:459321.

40. Lewis SJG, Barker RA. A pathophysiological model of freezing of gait in Parkinson's disease. Park Relat Disord. 2009;15 (5):333-338. doi:10.1016/j.parkreldis.2008.08.006

41. Nieuwboer A, Giladi N. Characterizing freezing of gait in Parkinson's disease: models of an episodic phenomenon. Mov Disord. 2013;28(11):1509-1519. doi:10.1002/mds.25683

42. Heremans E, Nieuwboer A, Spildooren J, et al. Cognitive aspects of freezing of gait in Parkinson's disease: a challenge for rehabilitation. J Neural Transm. 2013;120(4):543-557. doi:10.1007/ s00702-012-0964-y

43. Lewis SJG, Shine JM. The next step: a common neural mechanism for freezing of gait. Neuroscientist. 2016;22(1):72-82. doi:10.1177/1073858414559101

44. Weiss D, Schoellmann A, Fox MD, et al. Freezing of gait: understanding the complexity of an enigmatic phenomenon. Brain. 2020;143(1):14-30. doi:10.1093/brain/awz314

45. Craig CE, Jenkinson NJ, Brittain J-S, et al. Pedunculopontine nucleus microstructure predicts postural and gait symptoms in parkinson's disease. Mov Disord. 2020;35(7):1199-1207. doi: $10.1002 / \mathrm{mds} .28051$

46. Kim R, Lee J, Kim H-J, et al. CSF $\beta$-amyloid 42 and risk of freezing of gait in early Parkinson disease. Neurology. 2019;92 (1):E40-E47. doi:10.1212/WNL.0000000000006692

47. Wang L, Yan Y, Zhang L, et al. Substantia nigra neuromelanin magnetic resonance imaging in patients with different subtypes of Parkinson disease. J Neural Transm. 2021;128(2):171-179. doi:10.1007/s00702-020-02295-8

48. Pietracupa S, Suppa A, Upadhyay N, Giannì C. Gray and white matter changes in freezing of gait patients. View project exercise and brain modulation view project. Artic J Neurol. 2018;265 (1):52-62. doi:10.1007/s00415-017-8654-1

49. Tan SYZ, Keong NCH, Selvan RMP,et al. Periventricular white matter abnormalities on diffusion tensor imaging of postural instability gait disorder parkinsonism. Am J Neuroradiol. 2019;40:609-613.

50. Bharti K, Suppa A, Tommasin S,et al. Neuroimaging advances in Parkinson's disease with freezing of gait: a systematic review. NeuroImage Clin. 2019;24:102059. doi:10.1016/j.nicl.2019.102059

51. Tessitore A, Amboni M, Esposito F,et al. Resting-state brain connectivity in patients with Parkinson's disease and freezing of gait. Park Relat Disord. 2012;18(6):781-787. doi:10.1016/j. parkreldis.2012.03.018

52. Fling BW, Cohen RG, Mancini M,et al. Functional reorganization of the locomotor network in parkinson patients with freezing of gait. PLoS One. 2014;9:e100291. doi:10.1371/journal. pone. 0100291 
53. Mi TM, Mei -S-S, Liang -P-P, et al. Altered resting-state brain activity in Parkinson's disease patients with freezing of gait. $\mathrm{Sci}$ Rep. 2017;7:4792. doi:10.1038/s41598-017-16922-0

54. Snijders AH, et al. Gait-related cerebral alterations in patients with Parkinson's disease with freezing of gait. Brain. 2011;134 (1):59-72. doi:10.1093/brain/awq324

55. Myers PS, McNeely ME, Pickett KA, Duncan RP, Earhart GM. Effects of exercise on gait and motor imagery in people with Parkinson disease and freezing of gait. Park Relat Disord. 2018;53:89-95. doi:10.1016/j.parkreldis.2018.05.006

56. Toledo JB, López-Azcárate J, Garcia-Garcia D, et al. High beta activity in the subthalamic nucleus and freezing of gait in Parkinson's disease. Neurobiol Dis. 2014;64:60-65. doi:10.1016/ j.nbd.2013.12.005

57. Syrkin-Nikolau J, Koop MM, Prieto T, et al. Subthalamic neural entropy is a feature of freezing of gait in freely moving people with Parkinson's disease. Neurobiol Dis. 2017;108:288-297. doi:10.1016/j.nbd.2017.09.002

58. Maidan I, Fahoum F, Shustak S, et al. Changes in event-related potentials during dual task walking in aging and Parkinson's disease. Clin Neurophysiol. 2019;130(2):224-230. doi:10.1016/j. clinph.2018.11.019

59. Butler JS, Fearon C, Killane I, Waechter SM, Reilly RB, Lynch T. Motor preparation rather than decision-making differentiates Parkinson's disease patients with and without freezing of gait. Clin Neurophysiol. 2017;128(3):463-471. doi:10.1016/j. clinph.2016.12.019

60. Fearon C, Butler JS, Waechter SM, et al. Neurophysiological correlates of dual tasking in people with Parkinson's disease and freezing of gait. Exp Brain Res. 2020;239(1):175-187. doi:10.1007/s00221-020-05968-8

61. Rochester L, Galna B, Lord S, et al. Decrease in A $\beta 42$ predicts dopa-resistant gait progression in early Parkinson disease. Neurology. 2017;88(16):1501-1511. doi:10.1212/WNL.00000000 00003840

62. Kang JH, Irwin DJ, Chen-Plotkin AS. Association of cerebrospinal fluid $\beta$-amyloid 1-42, T-tau, P- tau181, and $\alpha$-Synuclein Levels with clinical features of drug- naive patients with early parkinson disease Ju-Hee. JAMA Neurol. 2014;70:1277-1287.

63. Alves G, Pedersen KF, Bloem BR, et al. Cerebrospinal fluid amyloid- $\beta$ and phenotypic heterogeneity in de novo Parkinson's disease. J Neurol Neurosurg Psychiatry. 2013;84(5):537-543. doi:10.1136/jnnp-2012-303808

64. Goldman JG, Andrews H, Amara A, et al. Cerebrospinal fluid, plasma, and saliva in the BioFIND study: relationships among biomarkers and Parkinson's disease features. Mov Disord. 2018;33(2):282-288. doi:10.1002/mds.27232

65. Gera A, O'Keefe JA, Ouyang B, et al. Gait asymmetry in glucocerebrosidase mutation carriers with Parkinson's disease. PLoS One. 2020;15:e0226494. doi:10.1371/journal.pone.0226494

66. Bloem BR, Grimbergen YAM, van Dijk JG, Munneke M. The 'posture second' strategy: a review of wrong priorities in Parkinson's disease. J Neurol Sci. 2006;248(1-2):196-204. doi:10.1016/j.jns.2006.05.010

67. Kelly VE, Eusterbrock AJ, Shumway-Cook A. A review of dualtask walking deficits in people with Parkinson's disease: motor and cognitive contributions, mechanisms, and clinical implications. Parkinsons Dis. 2012;2012:918719. doi: 10.1155/2012/918719

68. Shearin S, Medley A, Trudelle-jackson E, Swank C, Querry R. Gait \& posture differences in predictors for gait speed and gait endurance in Parkinson's disease. Gait Posture. 2021;87:49-53. doi:10.1016/j.gaitpost.2021.04.019

69. Bloem BR, Cramer M, Cramer M, Valkenburg VV. "Stops walking when talking" does not predict falls in parkinson' $\mathrm{s}$ disease. Ann Neurol. 2000;48(2):268. doi:10.1002/1531-8249(200008) $48: 2<268::$ AID-ANA21 $>3.0 . \mathrm{CO} ; 2-4$
70. Toulotte C, Thevenon A, Watelain E, Fabre C. Identification of healthy elderly fallers and non-fallers by gait analysis under dual-task conditions. Clin Rehabil. 2006;20(3):269-276. doi:10.1191/0269215506cr929oa

71. Amboni M, Cozzolino A, Longo K, Picillo M, Barone P. Freezing of gait and executive functions in patients with Parkinson's disease. Mov Disord. 2008;23(3):395-400. doi:10.1002/mds.21850

72. Bohnen NI, Albin RL. The cholinergic system in Parkinson's disease. Behav Brain Res. 2011;221:564-573.

73. Bohnen NI, Kaufer DI, Hendrickson R, et al. Cognitive correlates of cortical cholinergic denervation in Parkinson's disease and parkinsonian dementia. $J$ Neurol. 2006;253(2):242-247. doi:10.1007/s00415-005-0971-0

74. Bohnen NI, Kanel P, Zhou Z, et al. Cholinergic system changes of falls and freezing of gait in Parkinson's disease. Ann Neurol. 2019;85(4):538-549. doi:10.1002/ana.25430

75. Wilson J, Yarnall AJ, Craig CE, et al. Cholinergic basal forebrain volumes predict gait decline in parkinson's disease. Mov Disord. 2020;36:2021.

76. Rochester L, Yarnall AJ, Baker MR, et al. Cholinergic dysfunction contributes to gait disturbance in early Parkinson's disease. Brain. 2012;135(9):2779-2788. doi:10.1093/brain/aws207

77. Pelosin E, Ogliastro C, Lagravinese G, et al. Attentional control of gait and falls: is cholinergic dysfunction a common substrate in the elderly and Parkinson's disease? Front Aging Neurosci. 2016;8:1-7. doi:10.3389/fnagi.2016.00104

78. Henderson EJ, Lord SR, Brodie MA, et al. Rivastigmine for gait stability in patients with Parkinson's disease (ReSPonD): a randomised, double-blind, placebo-controlled, Phase 2 trial. Lancet Neurol. 2016;15(3):249-258. doi:10.1016/S1474-4422(15)00389-0

79. Hirsch EC, Graybielt ANNM, Duyckaertst C, Javoy-agid F. Neuronal loss in the pedunculopontine tegmental nucleus in Parkinson disease and in progressive supranuclear palsy. PNAS. 1987;84(16):5976-5980. doi:10.1073/pnas.84.16.5976

80. Rinne JO, Ma SY, Lee MS, Collan Y, Röyttä M. Loss of cholinergic neurons in the pedunculopontine nucleus in Parkinson's disease is related to disability of the patients. Park Relat Disord. 2008;14(7):553-557. doi:10.1016/j.parkreldis.2008.01.006

81. Shinotoh H, Namba H, Yamaguchi M, et al. Positron emission tomographic measurement of acetylcholinesterase activity reveals differential loss of ascending cholinergic systems in Parkinson's disease and progressive supranuclear palsy. Ann Neurol. 1999;46(1):62-69. doi:10.1002/1531-8249(199907)46:1<62::AID-ANA10>3.0.CO;2-P

82. Bohnen NI, Muller MLTM, Koeppe RA, et al. History of falls in Parkinson disease is associated with reduced cholinergic activity. Neurology. 2009;73(20):1670-1676. doi:10.1212/WNL.0b013e3 $181 \mathrm{c} 1$ ded6

83. Karachi C, Grabli D, Bernard FA, et al. Cholinergic mesencephalic neurons are involved in gait and postural disorders in Parkinson disease. J Clin Invest. 2010;120(8):2745-2754. doi:10.1172/JCI42642

84. Wang JY, Wang M-Y, Liu R-P, et al. Association analyses of autonomic dysfunction and sympathetic skin response in motor subtypes of parkinson's disease. Front Neurol. 2020;11:1-7. doi:10.3389/fneur.2020.577128

85. Banks S, Bayram E, Shan G, LaBelle D, Bluett B. Non-motor predictors of freezing of gait in Parkinson's disease. Gait Posture. 2019;68:311-316. doi:10.1016/j.gaitpost.2018.12.009

86. Thevathasan W, Cole MH, Graepel CL, et al. A spatiotemporal analysis of gait freezing and the impact of pedunculopontine nucleus stimulation. Brain. 2012;135(5):1446-1454. doi:10.1093/brain/aws039

87. Gallea C, Ewenczyk C, Degos B, et al. Pedunculopontine network dysfunction in Parkinson's disease with postural control and sleep disorders. Mov Disord. 2017;32(5):693-704. doi:10.1002/ mds. 26923 
88. Nobleza CMN, Siddiqui M, Shah PV,et al. The relationship of rapid eye movement sleep behavior disorder and freezing of gait in Parkinson's disease. Cureus. 2020;12:e12385.

89. Martens KAE, Silveira CRA, Intzandt BN, Almeida QJ. Overload from anxiety: a non-motor cause for gait impairments in Parkinson's disease. J Neuropsychiatry Clin Neurosci. 2018;30 (1):77-80. doi:10.1176/appi.neuropsych.16110298

90. Ehgoetz Martens KA, Lukasik EL, Georgiades MJ, et al. Predicting the onset of freezing of gait: a Longitudinal Study. Mov Disord. 2018;33(1):128-135. doi:10.1002/mds.27208

91. Sauerbier A, Jenner P, Todorova A, Chaudhuri KR. Parkinsonism and related disorders non motor subtypes and Parkinson , s disease. Park Relat Disord. 2016;22:S41-S46. doi:10.1016/j. parkreldis.2015.09.027

92. Contreras A, Grandas F. Risk of falls in Parkinson's disease: a Cross-Sectional Study of 160 patients. Parkinsons Dis. 2012;2012. doi:10.1155/2012/362572

93. Mancini M, Bloem BR, Horak FB, Lewis SJG. Clinical and methodological challenges for assessing freezing of gait: future perspectives assessing the presence and severity of FOG in clinical practice. Mov Disord. 2019;34:783-790.

94. Golbe LI, Pae J. Validity of a mailed epidemiological questionnaire and physical self-assessment in Parkinson's disease. Mov Disord. 1988;3(3):245-254. doi:10.1002/mds.870030309

95. Rathouz PJ, Kasper JD, Zeger SL, et al. Short-term consistency in self-reported physical functioning among elderly women: the Women's Health and Aging Study. Am J Epidemiol. 1998;147 (8):764-773. doi:10.1093/oxfordjournals.aje.a009521

96. Bloem BR, Beckley DJ, Van Hilten BJ, Roos RAC. Clinimetrics of postural instability in Parkinson's disease. J Neurol. 1998;245 (10):669-673. doi:10.1007/s004150050265

97. Brusse KJ, Zimdars S, Zalewski KR, Steffen TM. Testing functional performance in people with Parkinson disease. Phys Ther. 2005;85(2):134-141. doi:10.1093/ptj/85.2.134

98. McArdle R, Del Din S, Yarnall A. Gait analysis as a clinical tool for dementia: current perspectives and future challenges. Adv Clin Neurosci Rehabil. 2021;20. doi:10.47795/OBXA9271

99. Lord S, Rochester L, Baker K, Nieuwboer A. Concurrent validity of accelerometry to measure gait in Parkinsons disease. Gait Posture. 2008;27(2):357-359. doi:10.1016/j.gaitpost.2007.04.001

100. Morris ME, Iansek R, Matyas TA, Summers JJ. Stride length regulation in Parkinson's disease: normalization strategies and underlying mechanisms. Brain. 1996;119(2):551-568. doi:10.1093/brain/119.2.551

101. Sieberts SK, Schaff J, Duda M, et al. Crowdsourcing digital health measures to predict Parkinson's disease severity: the Parkinson's disease digital biomarker DREAM challenge. Npj Digit Med. 2021;4(1):1-12. doi:10.1038/s41746-021-00414-7

102. Morgan C, Craddock I, Tonkin EL, et al. Protocol for PD SENSORS: Parkinson's disease symptom evaluation in a naturalistic setting producing outcome measuRes using SPHERE technology. An observational feasibility study of multi-modal multi-sensor technology to measure symptoms and activities of d. BMJ Open. 2020;10(11):e041303. doi:10.1136/ bmjopen-2020-041303

103. Warmerdam E, Hausdorff JM, Atrsaei A, et al. Personal view long-term unsupervised mobility assessment in movement disorders. Lancet Neurol. 2020;19(5):462-470. doi:10.1016/ S1474-4422(19)30397-7

104. Varrecchia T, Castiglia SF, Ranavolo A, et al. An artificial neural network approach to detect presence and severity of Parkinson's disease via gait parameters. PLoS One. 2021;16(2):1-16. doi:10.1371/journal.pone.0244396

105. Mirelman A, Ben Or Frank M, Melamed M, et al. Detecting sensitive mobility features for parkinson's disease stages via machine learning. Mov Disord. 2021;Epub ahead:1-13.
106. Borzì L, Mazzetta I, Zampogna A, et al. Prediction of freezing of gait in parkinson's disease using wearables and machine learning. Sensors (Switzerland). 2021;21(2):1-19. doi:10.3390/s21020614

107. Torsney KM, Noyce AJ, Doherty KM, et al. Bone health in Parkinson's disease: a systematic review and meta-analysis. $J$ Neurol Neurosurg Psychiatry. 2014;85(10):1159-1166. doi:10.1136/jnnp-2013-307307

108. Henderson EJ, Lyell V, Bhimjiyani A, et al. Parkinsonism and related disorders management of fracture risk in Parkinson' $\mathrm{s}$ : a revised algorithm and focused review of treatments. Park Relat Disord. 2019;64:181-187. doi:10.1016/j.parkreldis.2019.03.021

109. Crotty GF, Schwarzschild MA. Chasing protection in Parkinson's disease: does exercise reduce risk and progression? Front Aging Neurosci. 2020;12:1-11. doi:10.3389/fnagi.2020.00186

110. Ni M, Hazzard JB, Signorile JF, Luca C. Exercise guidelines for gait function in parkinson's disease: a systematic review and meta-analysis. $J$ Neurol Rehabil. 2018;32(10):872-886. doi: $10.1177 / 1545968318801558$

111. Baker T, Pitman J, MacLellan MJ, Reed-Jones RJ. Visual cues promote head first strategies during walking turns in individuals with parkinson's disease. Front Sport Act Living. 2020;2:1-8.

112. Grobbelaar R, Venter R, Welman KE. Backward compared to forward over ground gait retraining have additional benefits for gait in individuals with mild to moderate Parkinson's disease: a randomized controlled trial. Gait Posture. 2017;58:294-299. doi:10.1016/j.gaitpost.2017.08.019

113. Yang YR, Cheng SJ, Lee YJ, Liu YC, Wang RY. Cognitive and motor dual task gait training exerted specific training effects on dual task gait performance in individuals with Parkinson's disease: a randomized controlled pilot study. PLoS One. 2019;14:1-12.

114. Intzandt B, Beck EN, Silveira CRA. The effects of exercise on cognition and gait in Parkinson's disease: a scoping review. Neurosci Biobehav Rev. 2018;95:136-169. doi:10.1016/j. neubiorev.2018.09.018

115. Walton C, Mowszowski L, Gilat M. Cognitive training for freezing of gait in Parkinson's disease: a randomized controlled trial. NPJ Park Dis. 2018;18(1):15. doi:10.1038/s41531-018-0052-6

116. Leung IHK, Walton CC, Hallock H, et al. Cognitive training in Parkinson disease: a systematic review and meta-analysis. Neurology. 2015;85(21):1843-1851. doi:10.1212/WNL.000 0000000002145

117. Nantel J, McDonald JC, Tan S, Bronte-Stewart H. Deficits in visuospatial processing contribute to quantitative measures of freezing of gait in Parkinson's disease. Neuroscience. 2012;221:151-156. doi:10.1016/j.neuroscience.2012.07.007

118. Geroin C, Nonnekes J, de Vries NM, et al. Does dual-task training improve spatiotemporal gait parameters in Parkinson's disease? Park Relat Disord. 2018;55:86-91. doi:10.1016/j. parkreldis.2018.05.018

119. Delgado-Alvarado M, Marano M, Santurtún A, et al. Nonpharmacological, nonsurgical treatments for freezing of gait in Parkinson's disease: a systematic review. Mov Disord. 2020;35 (2):204-214. doi:10.1002/mds.27913

120. Nadeau A, Lungu O, Duchesne C, et al. A 12-week cycling training regimen improves gait and executive functions concomitantly in people with parkinson's disease. Front Hum Neurosci. 2017;10:1-10. doi:10.3389/fnhum.2016.00690

121. Ni M, Signorile JF, Balachandran A, Potiaumpai M. Power training induced change in bradykinesia and muscle power in Parkinson's disease. Park Relat Disord. 2016;23:37-44. doi:10.1016/j.parkreldis.2015.11.028

122. Li F, Harmer P, Fitzgerald $\mathrm{K}$, et al. Tai Chi and postural stability in patients with Parkinson's disease. $N$ Engl J Med. 2012;366 (6):511-519. doi:10.1056/NEJMoa1107911 
123. Hass CJ, Buckley TA, Pitsikoulis C, Barthelemy EJ. Progressive resistance training improves gait initiation in individuals with Parkinson's disease. Gait Posture. 2012;35(4):669-673. doi:10.1016/j.gaitpost.2011.12.022

124. Capecci M, Serpicelli C, Fiorentini L, et al. Postural rehabilitation and kinesio taping for axial postural disorders in Parkinson's disease. Arch Phys Med Rehabil. 2014;95(6):1067-1075. doi:10.1016/j.apmr.2014.01.020

125. Debû B, De Oliveira Godeiro C, Lino JC, Moro E. Managing gait, balance, and posture in Parkinson's disease. Curr Neurol Neurosci Rep. 2018;18(5):23. doi:10.1007/s11910-018-0828-4

126. LVST Global. LVST-big programme: 2021. Available from: https:// www.lsvtglobal.com/LSVTBig. Accessed August 27, 2021.

127. Ebersbach G, Ebersbach A, Edler D, et al. Comparing exercise in Parkinson's disease - The Berlin LSVT ${ }^{\circledR}$ BIG Study. Mov Disord. 2010;25(12):1902-1908. doi:10.1002/mds.23212

128. Jonasson SB, Nilsson MH, Lexell J, Carlsson G. Experiences of fear of falling in persons with Parkinson's disease - a Qualitative Study. BMC Geriatr. 2018;18(1):1-10. doi:10.1186/s12877-0180735-1

129. Adkin AL, Frank JS, Jog MS. Fear of falling and postural control in Parkinson's disease. Mov Disord. 2003;18(5):496-502. doi:10.1002/mds. 10396

130. Ghielen I, Koene P, Twisk JW, et al. The association between freezing of gait, fear of falling and anxiety in Parkinson's disease: a longitudinal analysis. Neurodegener Dis Manag. 2020;10:159-168.

131. Barthel C, Nonnekes J, van Helvert M, et al. The laser shoes. Neurology. 2018;90(2):e164-e171. doi:10.1212/ WNL.0000000000004795

132. Ginis P, Heremans E, Ferrari A, et al. External input for gait in people with Parkinson's disease with and without freezing of gait: one size does not fit all. J Neurol. 2017;264(7):1488-1496. doi:10.1007/s00415-017-8552-6

133. Furnari A, Calabrò RS, De Cola MC, et al. Robotic-assisted gait training in Parkinson's disease: a three-month follow-up randomized clinical trial. Int J Neurosci. 2017;127(11):996-1004. doi: 10.1080/00207454.2017.1288623

134. Li R, Zhang Y, Jiang Y, et al. Rehabilitation training based on virtual reality for patients with Parkinson's disease in improving balance, quality of life, activities of daily living, and depressive symptoms: a systematic review and meta-regression analysis. Clin Rehabil. 2021;35(8):1089-1102. doi:10.1177/026921552 1995179

135. Bächlin M, Plotnik M, Roggen D, et al. Wearable assistant for Parkinsons disease patients with the freezing of gait symptom. IEEE Trans Inf Technol Biomed. 2010;14(2):436-446. doi:10.1109/TITB.2009.2036165

136. Arias P, Cudeiro J. Effect of rhythmic auditory stimulation on gait in parkinsonian patients with and without freezing of gait. PLoS One. 2010;5(3):e9675. doi:10.1371/journal.pone.0009675

137. Zhao Y, Nonnekes J, Storcken EJM, et al. Feasibility of external rhythmic cueing with the Google glass for improving gait in people with Parkinson's disease. J Neurol. 2016;263 (6):1156-1165. doi:10.1007/s00415-016-8115-2

138. Bryant MS, Rintala DH, Lai EC, Protas EJ. A pilot study: influence of visual cue color on freezing of gait in persons with Parkinson's disease. Disabil Rehabil Assist Technol. 2010;5 (6):456-461. doi:10.3109/17483107.2010.495815

139. Buated W, Sriyudthsak M, Sribunruangrit N, Bhidayasiri R. A low-cost intervention for improving gait in Parknson's disease patients: a cane providing visual cues. Eur Geriatr Med. 2012;3 (2):126-130. doi:10.1016/j.eurger.2012.01.006

140. Espay AJ, Baram Y, Dwivedi AK, et al. At-home training with closed-loop augmented-reality cueing device for improving gait in patients with Parkinson disease. J Rehabil Res Dev. 2010;47 (6):573-582. doi:10.1682/JRRD.2009.10.0165
141. Ahn D, Chung H, Lee HW, et al. Smart gait-aid glasses for Parkinson's disease patients. IEEE Trans Biomed Eng. 2017;64:2394-2402.

142. McCandless PJ, Evans BJ, Janssen J, et al. Effect of three cueing devices for people with Parkinson's disease with gait initiation difficulties. Gait Posture. 2016;44:7-11. doi:10.1016/j. gaitpost.2015.11.006

143. Harrington W, Greenberg A, King E, et al. Alleviating freezing of gait using phase-dependent tactile biofeedback. Conf Proc IEEE Eng Med Biol Soc. 2016;2016:5841-5844. doi:10.1109/ EMBC.2016.7592056

144. Rosenthal L, Sweeney D, Cunnington AL, Quinlan LR, Ólaighin G. Sensory electrical stimulation cueing may reduce freezing of gait episodes in Parkinson's disease. J Healthc Eng. 2018;2018:1-6. doi:10.1155/2018/4684925

145. Mancini M, Smulders K, Harker G, Stuart S, Nutt JG. Assessment of the ability of open- and closed-loop cueing to improve turning and freezing in people with Parkinson's disease. Sci Rep. 2018;8 (1):1-9. doi:10.1038/s41598-018-31156-4

146. Mak M, Wong-Yu I, Chung C, Chung CL. Long-term effects of exercise and physical therapy in people with Parkinson disease. Nat Rev Neurol. 2017;13:689-703. doi:10.1038/ nrneurol.2017.128

147. Ellis T, Boudreau JK, DeAngelis TR, et al. Barriers to exercise in people with parkinson disease. Phys Ther. 2013;93(5):628-636. doi:10.2522/ptj.20120279

148. Smulders K, Dale ML, Carlson-Kuhta P, et al. Pharmacological treatment in Parkinson's disease: effects on gait. Park Relat Disord. 2017;31:3-13. doi:10.1016/j.parkreldis.2016.07.006

149. Curtze C, Nutt JG, Carlson-Kuhta P, Mancini M, Horak FB. Levodopa is a double-edged sword for balance and gait in people with Parkinson's disease. Mov Disord. 2015;30(10):1361-1370. doi: $10.1002 / \mathrm{mds} .26269$

150. Sterling NW, Cusumano JP, Shaham N, et al. Dopaminergic modulation of arm swing during gait among Parkinson's disease patients. J Parkinsons Dis. 2015;5(1):141-150. doi:10.3233/JPD140447

151. Fietzek UM, Zwosta J, Schroeteler FE, Ziegler K, CeballosBaumann AO. Levodopa changes the severity of freezing in Parkinson's disease. Park Relat Disord. 2013;19(10):894-896. doi:10.1016/j.parkreldis.2013.04.004

152. Olanow C, Hurtig H, Stern M, et al. A multicenter double-blind placebo-controlled trial of pergolide as an adjunct to sinemet in Parkinson's disease. Mov Disord. 1994;9(1):40-47. doi:10.1002/ mds.870090107

153. Schrag A, Hommel ALAJ, Lorenzl S, et al. The late stage of Parkinson's -results of a large multinational study on motor and non-motor complications. Park Relat Disord. 2020;75:91-96. doi:10.1016/j.parkreldis.2020.05.016

154. Stuart S, Morris R, Giritharan A, et al. Prefrontal cortex activity and gait in Parkinson's disease with cholinergic and dopaminergic therapy. Mov Disord. 2020;35(11):2019-2027. doi:10.1002/ mds. 28214

155. Mancini M, Chung K, Zajack A, et al. Effects of augmenting cholinergic neurotransmission on balance in Parkinson's disease. Park Relat Disord. 2019;69:40-47. doi:10.1016/j. parkreldis.2019.10.022

156. Lauretani F, Galuppo L, Costantino C, et al. Parkinson's disease (PD) with dementia and falls is improved by AChEI? A Preliminary Study report. Aging Clin Exp Res. 2016;28 (3):551-555. doi:10.1007/s40520-015-0437-x

157. Chung KA, Lobb BM, Nutt JG, Horak FB. Effects of a central cholinesterase inhibitor on reducing falls in Parkinson disease. Neurology. 2010;75(14):1263-1269. doi:10.1212/WNL.0b013e3 $181 \mathrm{f} 6128 \mathrm{c}$ 
158. Litvinenko IV, Odinak MM, Mogil'naya VI, Emelin AYU. Efficacy and safety of galantamine (reminyl) for dementia in patients with Parkinson's disease (an open controlled trial). Neurosci Behav Physiol. 2008;38(9):937-945. doi:10.1007/ s11055-008-9077-3

159. Li Z, Yu Z, Zhang J, et al. Impact of rivastigmine on cognitive dysfunction and falling in Parkinson's disease patients. Eur Neurol. 2015;74(1-2):86-91. doi:10.1159/000438824

160. Emre M, Poewe W, De Deyn PP, et al. Long-term safety of rivastigmine in parkinson disease dementia: an Open-Label, Randomized Study. Clin Neuropharmacol. 2014;37(1):9-16. doi:10.1097/WNF.0000000000000010

161. Dubois B, Tolosa E, Katzenschlager R, et al. Donepezil in Parkinson's disease dementia: a randomized, double-blind efficacy and safety study. Mov Disord. 2012;27(10):1230-1238. doi: $10.1002 / \mathrm{mds} .25098$

162. Emre M, Aarsland D, Albanese A, et al. Rivastigmine for dementia associated with Parkinson's disease. N Engl J Med. 2004;351 (24):2509-2518. doi:10.1056/NEJMoa041470

163. Scheife R, Takeda M. Central nervous system safety of anticholinergic drugs for the treatment of overactive bladder in the elderly. Clin Ther. 2005;27(2):144-153. doi:10.1016/j. clinthera.2005.02.014

164. Malkani R, Zadikoff C, Melen O, Videnovic A, Borushko E,ST, Simuni T. Amantadine for freezing of gait in patients with Parkinson's disease. Clin Neuropharmacol. 2012;35(6):266-268. doi:10.1097/WNF.0b013e31826e3406

165. Kestenbaum M, Abu Snineh M, Nussbaum T, et al. Repeated intravenous amantadine infusions in advanced parkinsonism: experience of a large movement disorder center. ISR Med Assoc J. 2019;21:812-816

166. Kim YE, Yun JY, Yang HJ, et al. Intravenous amantadine for freezing of gait resistant to dopaminergic therapy: a randomized, double-blind, placebo-controlled, cross-over clinical trial. PLoS One. 2012;7(11):e48890. doi:10.1371/journal.pone.0048890

167. Lee JY, Oh S, Kim JM, et al. Intravenous amantadine on freezing of gait in Parkinson's disease: a randomized controlled trial. $J$ Neurol. 2013;260(12):3030-3038. doi:10.1007/s00415-0137108-7

168. Moreau C, Delval A, Tiffreau V, et al. Memantine for axial signs in Parkinson's disease: a Randomised, Double-Blind, PlaceboControlled Pilot Study. J Neurol Neurosurg Psychiatry. 2013;84 (5):552-555. doi:10.1136/jnnp-2012-303182

169. Auriel E, Hausdorff JM, Herman T, Simon ES, Giladi N. Effects of methylphenidate on cognitive function and gait in patients with Parkinson's disease: a Pilot Study. Clin Neuropharmacol. 2006;29 (1):15-17. doi:10.1097/00002826-200601000-00005

170. Nutt JG, Carter JH, Carlson NE. Effects of methylphenidate on response to oral levodopa: a double-blind clinical trial. Arch Neurol. 2007;64(3):319-323. doi:10.1001/ archneur.64.3.319

171. Delval A, Moreau C, Bleuse S, et al. Gait and attentional performance in freezers under methylphenidate. Gait Posture. 2015;41 (2):384-388. doi:10.1016/j.gaitpost.2014.10.022

172. Espay AJ, Dwivedi AK, Payne M, et al. Methylphenidate for gait impairment in Parkinson disease: a randomized clinical trial. Neurology. 2011;76(14):1256-1262. doi:10.1212/WNL.0b013 e3 182143537

173. Luca CC, Singer C. 4-Aminopyridine improves freezing of gait in Parkinson's disease. J Neurol. 2013;260(10):2662-2664. doi:10.1007/s00415-013-7090-0

174. Luca C, Nadayil G, Dong C, et al. Dalfampridine in Parkinson's disease related gait dysfunction: a randomized double blind trial. J Neurol Sci. 2017;15:7-11. doi:10.1016/j.jns.2017.05.011
175. Kitagawa M, Houzen H, Tashiro K. Effects of caffeine on the freezing of gait in Parkinson's disease. Mov Disord. 2007;22 (5):710-712. doi:10.1002/mds.21208

176. Matsuura K, Kajikawa H, Tabei K-I, et al. The effectiveness of istradefylline for the treatment of gait deficits and sleepiness in patients with Parkinson's disease. Neurosci Lett. 2018;662:158-161. doi:10.1016/j.neulet.2017.10.018

177. Iijima M, Orimo S, Terashi H, et al. Efficacy of istradefylline for gait disorders with freezing of gait in Parkinson's disease: a single-arm, open-label, prospective, multicenter study. Expert Opin Pharmacother. 2019;20(11):1405-1411. doi:10.1080/ 14656566.2019.1614167

178. Rahimpour S, Gaztanaga W, Yadav AP, et al. Freezing of Gait in Parkinson's Disease: Invasive and Noninvasive Neuromodulation. Neuromodulation. 2021;24(5):829-842. doi:10.1111/ner.13347

179. Huang C, Chu H, Zhang Y, Wang X. Deep brain stimulation to alleviate freezing of gait and cognitive dysfunction in Parkinson's disease: update on current research and future perspectives. Front Neurol. 2018;12:29. doi:10.3389/fnins.2018.00029

180. Roper JA, Kang N, Ben J, et al. Deep brain stimulation improves gait velocity in Parkinson's disease: a systematic review and meta-analysis. J Neurol. 2016;263(6):1195-1203. doi:10.1007/ s00415-016-8129-9

181. Johnsen EL, Mogensen PH, Sunde NA, Østergaard K. Improved asymmetry of gait in Parkinson's disease with DBS: gait and postural instability in Parkinson's disease treated with bilateral deep brain stimulation in the subthalamic nucleus. Mov Disord. 2009;24(4):588-595. doi:10.1002/mds.22419

182. Scholten M, Klemt J, Heilbronn M, et al. Effects of subthalamic and nigral stimulation on gait kinematics in Parkinson's disease. Front Neurol. 2017;8:1-8. doi:10.3389/fneur.2017.00543

183. Xie T, Vigil J, MacCracken E, et al. Low-frequency stimulation of STN-DBS reduces aspiration and freezing of gait in patients with PD. Neurology. 2015;84(4):415-420. doi:10.1212/WNL.0000000000001184

184. Yu K, Ren Z, Guo S, Li J, Li Y. Effects of pedunculopontine nucleus deep brain stimulation on gait disorders in Parkinson's disease: a meta-analysis of the literature. Clin Neurol Neurosurg. 2020;198:106108. doi:10.1016/j.clineuro.2020.106108

185. Weiss D, Walach M, Meisner C, et al. Nigral stimulation for resistant axial motor impairment in Parkinson's disease? A randomized controlled trial. Brain. 2013;136(7):2098-2108. doi:10.1093/brain/awt122

186. Brosius SN, Gonzalez CL, Shuresh J, Walker HC. Reversible improvement in severe freezing of gait from Parkinson's disease with unilateral interleaved subthalamic brain stimulation. Park Relat Disord. 2015;21(12):1469-1470. doi:10.1016/j. parkreldis.2015.09.047

187. Fonoff ET, de Lima-pardini AC, Coelho DB, Monaco BA, Machado B. Spinal cord stimulation for freezing of gait: from bench to bedside. Front Neurol. 2019;27(10):905. doi:10.3389/ fneur.2019.00905

188. Fonoff E, Junior ER, Araújo MFPD, et al. History of and insights into spinal cord stimulation in Parkinson disease. $J$ Neurol Rehabil. 2020;34(11):967-978. doi:10.1177/ 1545968320956984

189. Nardone R, Versace V, Brigo F, et al. Transcranial magnetic stimulation and gait disturbances in Parkinson's disease: a systematic review. Neurophysiol Clin. 2020;50(3):213-225. doi:10.1016/j.neucli.2020.05.002

190. Khedr EM, Rothwell JC, Shawky OA, Ahmed MA, Hamdy A. Effect of daily repetitive transcranial magnetic stimulation on motor performance in Parkinson's disease. Mov Disord. 2006;21 (12):2201-2205. doi:10.1002/mds.21089 
191. Lomarev MP, Kanchana S, Bara-Jimenez W, et al. Placebocontrolled study of rTMS for the treatment of Parkinson's disease. Mov Disord. 2006;21(3):325-331. doi:10.1002/mds.20713

192. Su M, Hyuk W, Whan J, Youn J, Kwan Y. Efficacy of cumulative high-frequency rTMS on freezing of gait in Parkinson 's disease. Restor Neurol Neurosci. 2015;33:521-530.

193. Workman CD, Fietsam AC, Rudroff T. Tolerability and blinding of transcranial direct current stimulation in people with parkinson's disease: a critical review. Brain Sci. 2020;10:1-21.
194. Costa-ribeiro A, Maux A, Bosford T, et al. Transcranial direct current stimulation associated with gait training in Parkinson, s disease: a pilot randomized clinical trial. Dev Neurorehabil. 2017;20(3):121-128. doi:10.3109/17518423.2015.1131755

195. Mishra R, Thrasher AT. Transcranial direct current stimulation of dorsolateral prefrontal cortex improves dual-task gait performance in patients with Parkinson's disease: a Double Blind, Sham-Controlled Study. Gait Posture. 2021;84:11-16. doi:10.1016/j.gaitpost.2020.11.012

\section{Publish your work in this journal}

Neuropsychiatric Disease and Treatment is an international, peerreviewed journal of clinical therapeutics and pharmacology focusing on concise rapid reporting of clinical or pre-clinical studies on a range of neuropsychiatric and neurological disorders. This journal is indexed on PubMed Central, the 'PsycINFO' database and CAS, and is the official journal of The International Neuropsychiatric Association (INA). The manuscript management system is completely online and includes a very quick and fair peer-review system, which is all easy to use. Visit http://www.dovepress.com/testimonials.php to read real quotes from published authors. 